\title{
PIF4/HEMERA-mediated daytime thermosensory growth requires the Mediator subunit MED14
}

3 Abhishesh Bajracharya ${ }^{1}$, Jing Xi ${ }^{2}$, Karlie F. Grace ${ }^{1}$, Eden E. Bayer ${ }^{1}$, Chloe A. Grant ${ }^{1}$, Caroline

$5 \quad{ }^{1}$ Department of Biology, University of Mississippi, Oxford, MS 38677, USA

$6 \quad{ }^{2}$ Natural Products Utilization Research Unit, U.S. Department of Agriculture, Agricultural

7 Research Service, Oxford, Mississippi, USA

$8{ }^{3}$ National Center for Natural Products Research, School of Pharmacy, University of Mississippi,

9 Oxford, Mississippi, USA

$10{ }^{4}$ Division of Pharmacology, Department of BioMolecular Sciences, School of Pharmacy,

11 University of Mississippi, Oxford, Mississippi, USA

$12{ }^{5}$ Corresponding author

14 Address correspondence to Yongjian Qiu (yqiu@ olemiss.edu)

16 One-sentence summary:

17 The Mediator subunit MED14 promotes thermomorphogenesis by interacting with

18 PHYTOCHROME-INTERACTING FACTOR 4 and HEMERA to induce the expression of

19 growth-promoting genes at elevated temperatures.

20 Keywords

21 Thermomorphogenesis

22 Mediator complex

23 Phytochrome-Interacting Factors (PIFs)

24 Auxin 


\section{Abstract}

30 While moderately elevated ambient temperatures do not trigger stress responses in plants, they

31 do significantly stimulate the growth of specific organs through a process known as

32 thermomorphogenesis. The basic helix-loop-helix transcription factor PHYTOCHROME-

33 INTERACTING FACTOR 4 (PIF4) plays a central role in regulating thermomorphogenetic

34 hypocotyl elongation in various plant species, including Arabidopsis thaliana. Although it is well

35 known that PIF4 promotes plant thermosensory growth by activating genes involved in the

36 biosynthesis and signaling of the phytohormone auxin, the detailed molecular mechanism of

37 such transcriptional activation is not clear. Our previous studies demonstrated that HEMERA

38 (HMR), a transcriptional co-activator of PIF4, promotes the thermo-induced expression of PIF4

39 target genes through its nine-amino-acid transactivation domain (9aaTAD). In this report, we

40 investigate the role of the Mediator complex in the PIF4/HMR-mediated thermoresponsive gene

41 expression. Through the characterization of various mutants of the Mediator complex, a tail

42 subunit named MED14 is identified as an essential factor for thermomorphogenetic hypocotyl

43 growth. MED14 is required for the thermal induction of PIF4 target genes but has a marginal

44 effect on the levels of PIF4 and HMR. Further transcriptomic analyses confirm that the

45 expression of numerous PIF4/HMR-dependent, auxin-related genes requires MED14 at warm

46 temperatures. Moreover, PIF4 and HMR physically interact with MED14 and both are

47 indispensable for the association of MED14 with the promoters of these thermoresponsive genes.

48 Taken together, these results unveil an important thermomorphogenetic mechanism, in which

49 PIF4 and HMR recruit the Mediator complex to activate auxin-related growth-promoting genes

50 when plants sense moderate increases in ambient temperature. 


\section{Introduction}

Plants are highly sensitive to environmental temperature changes. Moderately elevated ambient temperatures below heat shock (between $12{ }^{\circ} \mathrm{C}$ and $27^{\circ} \mathrm{C}$ ) do not trigger stress responses, but they may drastically alter plant growth and development, including rapid stem and root elongation, enhanced petiole hyponastic growth, early flowering, and reduced stomatal index. Collectively, these responses are referred to as thermomorphogenesis (Casal and Balasubramanian, 2019; Ludwig et al., 2021; Park et al., 2021).

Thermomorphogenetic responses, such as thermosensory hypocotyl elongation, involve massive transcriptomic reprogramming, as demonstrated in the model dicotyledonous plant Arabidopsis thaliana (Liu and Charng, 2013; Sidaway-Lee et al., 2014; Cortijo et al., 2017; Ding et al., 2018; Han et al., 2019; Bordiya et al., 2020; Jin et al., 2020; Lee et al., 2020; Lee et al., 2021b; Lee et al., 2021c). A major effect of this transcriptomic reprogramming is to activate genes involved in auxin synthesis, such as YUCCA8 (YUC8), and auxin signaling, such as INDOLE-3-ACETIC ACID INDUCIBLE 19 \& 29 (IAA19 \& IAA29) (Franklin et al., 2011; Sun et al., 2012; Ma et al., 2016; Zhu et al., 2016). PHYTOCHROME-INTERACTING FACTOR 4 (PIF4), a central transcriptional regulator of thermomorphogenesis (Qiu, 2020), activates these auxin-related genes in response to warm temperatures (Franklin et al., 2011; Sun et al., 2012; Ma et al., 2016; Zhu et al., 2016). PIF4 belongs to an eight-member basic Helix-Loop-Helix (bHLH) transcription factor family, which was first identified as a key player in transducing light signals perceived by the red/far-red photoreceptors known as phytochromes (Leivar and Quail, 2011). PIFs are integrators of light and various environmental and developmental signals (Leivar and Quail, 2011; Leivar and Monte, 2014; Pham et al., 2018). Although PIFs show apparent functional redundancy in multiple morphogenetic responses (Leivar and Monte, 2014; Pham et al., 2018), thermomorphogenesis is mediated primarily through PIF4 (Koini et al., 2009; Stavang et al., 2009; Kumar et al., 2012; Qiu et al., 2019). As an early ambient temperature signaling component, PIF4 is regulated at multiple levels, including transcription, post-translational modification, DNA-binding affinity, transcriptional activity, and protein stability (Qiu, 2020). Recent reports revealed distinct temperature-signaling mechanisms under different light conditions or photoperiod regimes, indicating more complex regulation of PIF4-mediated thermal responses by light quality, day length, and the circadian clock (Box et al., 2015; Park et al., 2017; Qiu et al., 2019).

Besides its role in thermomorphogenesis, PIF4 also activates growth-promoting genes during skotomorphogenesis (growth in darkness) and shade-avoidance responses (Leivar and Monte, 2014). PIF4 possesses a transactivation domain (TAD) that resembles that of PIF3 (Dalton et al., 2016; Yoo et al., 2021). The tomato PIF4 activates shade-induced genes by interacting with MED25, a tail component of the Mediator complex (Sun et al., 2020). These data suggest that PIF4 has a functional TAD that promotes shade-avoidance responses. However, whether PIF4's TAD is equally important for its activity in thermomorphogenesis is unknown. We previously 
demonstrated that PIF4-mediated thermomorphogenetic control of growth-promoting gene expression requires the transcriptional coactivator HEMERA (HMR) (Qiu et al., 2019). HMR physically interacts with PIF4 and activates the thermo-inducible PIF4 target genes through an acidic nine-amino-acid transactivation domain (9aaTAD). A weak allele named $h m r$-22 harbors a D516N mutation in the 9aaTAD, largely disrupting HMR's transactivation activity and leading to defects in the thermosensory growth (Qiu et al., 2015; Qiu et al., 2019). Mechanistic insights into the function of HMR's TAD in regulating PIF4 activity have yet to be revealed.

HMR's 9aTAD resembles the TADs present in prototypic acidic transcription activators, such as VP16, GAL4, GCN4, and MYC (Piskacek et al., 2007). These acidic TADs interact directly with subunits of the Mediator complex to facilitate the assembly or the stability of the RNA polymerase II (Pol II) preinitiation complex (PIC) at the transcriptional initiation site (Borggrefe and Yue, 2011; Vojnic et al., 2011). The Mediator complex is a multi-subunit transcriptional coordinator that transmits signals from transcription activators to the Pol II preinitiation transcription activators and is required for the transcription of virtually all Pol II-transcribed genes (Dolan et al., 2017).

Much of our current understanding of the three-dimensional structure of the Mediator complex has come from studies performed in yeast and mammals (Robinson et al., 2016; Nozawa et al., 2017; Schilbach et al., 2017; Tsai et al., 2017; Chen et al., 2021; Rengachari et al., 2021). and metazoans, more than 20 MED subunits are conserved across yeast, plants, and metazoans (Bourbon, 2008). Furthermore, the Mediator complexes in all three Kingdoms share a generally similar modular composition, with subunits organized into head, middle, tail, and kinase subcomplexes (Malik and Roeder, 2010; Buendía-Monreal and Gillmor, 2016; Dolan and Chapple, 2017). The head and middle modules form the essential core Mediator that directly interacts with PIC (Nozawa et al., 2017; Schilbach et al., 2017). PIC-Mediator assembly further creates a Head-Middle sandwich to stabilize two Pol II C-terminal domain (CTD) segments and position CTD for phosphorylation (Chen et al., 2021). In contrast to the head and middle subunits, the subunits of the tail module are relatively loosely associated with each other and are targeted by activators and repressors (Malik and Roeder, 2010; Cevher et al., 2014; Zhao et al., 2021).

To further elucidate the molecular mechanism by which PIF4 and HMR recruit the transcriptional machinery when activating the expression of thermoresponsive genes, we performed a reverse genetic screen for Arabidopsis Mediator mutants that show reduced sensitivity to moderate temperature elevations. Here, we report the identification of MED14 as a key subunit of the Mediator complex that is recruited by PIF4 and HMR to activate auxin- 


\section{Results}

\section{MED14 is required for daytime thermosensory hypocotyl growth}

To investigate the role of the Mediator complex in thermomorphogenesis and search for Mediator subunits that work with PIF4 and HMR to induce the transcription of thermoresponsive genes, we first tested the thermal sensitivity of mutants of various Mediator subunits. Most mutants of the Mediator subunits in the head, middle, and kinase modules showed similar responses to the warm temperature as wild type - the ratio of hypocotyl length between $27^{\circ} \mathrm{C}$ and $20^{\circ} \mathrm{C}$ were comparable with those in the wild-type seedlings (Supplemental Figure S1). In comparison, mutants of several tail subunits, including MED14, MED16, and MED25, were hyposensitive to the increased temperature (Figure 1A-C). The ratios of hypocotyl length at 27 ${ }^{\circ} \mathrm{C}$ to that at $20{ }^{\circ} \mathrm{C}$ in med14 (SAIL_373_C07), med16-2 (SALK_048091), med16-3 (WISCDSLOX504A08), med25-2 (SALK_129555C), and med25-3 (SALK_059316C) were significantly lower than those of wild-type seedlings (Figure 1C). Among these mutants, med14 showed the most dramatic reduction in thermomorphogenetic hypocotyl growth - it had only $37 \%$ of the wild-type thermal response and $\sim 70 \%$ of the wild-type hypocotyl length at $27{ }^{\circ} \mathrm{C}$.

The med14 mutant (SAIL_373_C07) was the only viable T-DNA insertion line with dramatically reduced MED14 expression (Zhang et al., 2013). To further confirm that the thermomorphogenetic defect of med14 is caused by decreased MED14 levels, we generated MED14 overexpression lines in the med14 mutant background. A full-length MED14 CDS driven by the $35 \mathrm{~S}$ Cauliflower Mosaic Virus (CaMV) constitutive promoter was expressed with a C-terminal human influenza hemagglutinin (HA) tag. The resulting transgenic plants, designated 35S::MED14-HA/med14, successfully complemented the morphological phenotype of med14 at $27^{\circ} \mathrm{C}$ and largely rescued its reduced sensitivity in thermomorphogenetic hypocotyl growth (Figure 1D-F). These data suggest that MED14 plays a crucial role in Arabidopsis thermosensory growth.

\section{MED14 regulates the thermal induction of key auxin-related PIF4 targets}

PIF4 and HMR promote thermosensory hypocotyl growth by activating key genes in auxin biosynthesis (e.g., YUC8) and signaling (e.g., IAA19 and IAA29). The identification of MED14's role in thermomorphogenesis prompted us to test whether MED14 is the tail component that works with PIF4 and HMR in activating the expression of these growth-related, thermo-induced genes. Toward this end, we first examined the steady-state transcript levels of $Y U C 8, I A A 19$, and IAA29 in 4-d-old Col-0 and med14 seedlings grown at lower and warmer temperatures. While the transcription of all three genes was stimulated at $27^{\circ} \mathrm{C}$ in Col-0, these increases were not observed in med14 (Figure 2A). Similarly, a 6-hour warm temperature treatment greatly induced the expression levels of all three markers in Col-0, but not in the med14 mutant (Figure 2B). 
173 Given that the Mediator complex is essential for all Pol II-mediated transcription (Jeronimo and 174 Robert, 2017; Soutourina, 2018) and that MED14 is a key component of the Mediator complex 175 (Buendía-Monreal and Gillmor, 2016; Yang et al., 2016), the hypomorphic mutation in med14 176 might also affect the expression of PIF4 and HMR. Indeed, the absolute transcript levels of $H M R$ 177 and PIF4 in the med14 mutant were lower than those in Col-0 at $27{ }^{\circ} \mathrm{C}$ (Figure $2 \mathrm{~A}$ ). In addition, 178 the thermo-induced expression of PIF4, but not HMR, was also compromised in med14 (Figure 179 2B). We further examined whether the med14 mutation also affected the HMR and PIF4 expression at the protein level. While no significant difference in the HMR protein level between Col-0 and med14 seedlings was observed after the thermal treatment (a 20-to- $27{ }^{\circ} \mathrm{C}$ transition), the PIF4 protein level was slightly reduced in the med14 mutant when compared with Col-0 (Figure 2C). These data imply that MED14 might contribute to the thermoresponsive expression of the PIF4/HMR-regulated genes (YUC8, IAA19, and IAA29) in two ways - a direct role by assisting PIF4's and HMR's transactivation activity and an indirect role by modulating the levels of PIF4 and HMR when plants are exposed to warmer temperatures.

MED14, HMR, and PIF4 co-regulate a subset of thermoresponsive genes

Previous transcriptomic analyses by other groups have shown that 4-16\% of Arabidopsis genes are differentially regulated by warm temperatures and the expression of a large portion of these thermo-regulated genes requires PIF4 (Ding et al., 2018; Jin et al., 2020; Kim et al., 2020; Lee et al., 2020; Lee et al., 2021b; Lee et al., 2021c). The observation that MED14 is indispensable for the thermal induction of several key PIF4/HMR target genes motivated us to further explore its correlation with PIF4 and HMR in controlling the thermoresponsive gene expression on the genome-wide scale. Therefore, we performed RNA-seq on 4-day-old Col-0, pif4-2, hmr-22, and med 14 seedlings grown at $20^{\circ} \mathrm{C}$ and $27^{\circ} \mathrm{C}$ under continuous red light.

When comparing expression levels at $27{ }^{\circ} \mathrm{C}$ with those at $20{ }^{\circ} \mathrm{C}, 828$ and 938 genes were induced and repressed at least 2-fold by warmer temperature in Col-0 (FDR $p$-value $<0.001$, FPKM > 1), respectively (Figure 3A; Supplemental Dataset 1). These results are in agreement with previous studies in which similar growth conditions were used (Lee et al., 2020; Lee et al., 2021c). For example, 483 of 828 thermo-induced genes (58\%) and 550 out of 938 (59\%) thermorepressed genes in the current study overlapped with at least one study reported by Lee et al. 2020 and Lee et al. 2021b (Supplemental Figure S2; Supplemental Dataset 2). The pif4-2, hmr22 , and med14 mutants displayed distinct transcriptome profiles compared with Col-0 and a large proportion of genes were uniquely induced or repressed at $27^{\circ} \mathrm{C}$ in each mutant (Figure 3A; Supplemental Dataset 1). Even though several genes were also shared between Col-0 and each mutant, 324 and $281 \mathrm{SSTF}$ genes were uniquely induced and repressed in Col-0 at $27{ }^{\circ} \mathrm{C}$, respectively (Figure 3A, Supplemental Figure S3A; Supplemental Dataset 3). We, therefore, named these genes as PIF4/HMR/MED14-dependent thermo-induced and thermo-repressed 211 genes. We performed Gene Ontology (GO) analysis on these two groups of thermo-regulated 212 genes. Notably, many genes involved in growth-related phytohormone signaling (e.g., auxin, 
brassinosteroid, and ethylene) were upregulated in Col-0 but not in these three mutants, and a number of genes involved in cell wall organization and modification were downregulated only in Col-0 (Figure 3B). This observation is consistent with the thermomorphogenetic hypocotyl growth phenotype of these genotypes (Figure 1B, C).

To evaluate whether these PIF4/HMR/MED14-dependent thermoresponsive genes are directly or indirectly regulated by PIF4, we compared our datasets with published PIF4-associated genes from three studies (Supplemental Dataset 4). Possibly due to different growth conditions and treatment methods, the number of PIF4-binding genes identified through ChIP-seq assays in the three studies varied from $~ 1,000$ to over 7,000 (Oh et al., 2012; Pfeiffer et al., 2014; Pedmale et al., 2016). We defined the thermo-regulated PIF4 direct targets as the PIF4/HMR/MED14dependent thermoresponsive genes that were identified in at least two of the three published studies. While less than $10 \%$ of the thermo-repressed genes (25 out of 281) were associated with PIF4, about one-third of the thermo-induced genes (114 out of 324) are PIF4 direct targets (Supplemental Figure S3B; Supplemental Dataset 4). Therefore, MED14 may mainly function as a coactivator, rather than a repressor, in regulating thermoresponsive PIF4 targets. GO analyses of these two datasets showed similar results as those of PIF4/HMR/MED14-dependent thermoresponsive genes (Supplemental Figure S3C). Many auxin-responsive genes, including IAA19, IAA29, and a group of SMALL AUXIN UP RNA (SAUR) genes, were enriched in the PIF4/HMR/MED14-dependent thermo-induced PIF4 targets; several genes involved in cell wall modification and lignin metabolic process were enriched in PIF4/HMR/MED14-dependent thermo-repressed PIF4 targets (Supplemental Figure S3C).

We further performed RT-qPCR analyses to confirm the RNA-seq results (Figure 3C, D). The expression of three PIF4/HMR/MED14-dependent thermo-induced genes, ST2A (AT5G07010), APD7 (AT5G02760), and ARGOS (AT3G59900), were highly induced in Col-0 at $27^{\circ} \mathrm{C}$ but showed similar levels at lower and warmer temperatures in pif4-2, hmr-22, and med14 mutants (Figure 3C). The expression of three PIF4/HMR/MED14-dependent thermo-repressed genes, RING (AT1G24580), SCPL31 (AT1G11080), and MES18 (AT5G58310), were greatly reduced in Col-0 at $27^{\circ} \mathrm{C}$ but not in those three mutants (Figure 3D). Taken together, these data suggest that MED14 co-regulates a group of growth-related, thermoresponsive genes with PIF4 and HMR.

\section{PIF4 and HMR physically interact with MED14 through their TADs} The thermomorphogenetic defect of med14 and the requirement of MED14 for the thermal induction of many PIF4 direct targets suggest that it may be the Mediator tail subunit that communicates with PIF4 and/or HMR during the transcriptional activation of those thermoresponsive genes. To test this hypothesis, we investigated the interactions between MED14 and PIF4/HMR. We first expressed PIF4 and HMR as Glutathione S-transferase (GST) fusion proteins in $E$. coli and used them as baits to test their interactions with in-vitro 
transcribed/translated HA-MED14. Both GST-HMR and GST-PIF4 appear to interact strongly with HA-MED14 (Figure 4A).

We further confirmed the interactions between PIF4 and MED14 using Bimolecular fluorescence complementation (BiFC) assays. When expressed in Nicotiana benthamiana, PIF4-NmVen210 interacted with MED14-cVen210 but not with cVen210 alone (Figure 4B). We did not observe the yellow fluorescent signal when co-expressing HMR-NmVen210 and MED14-cVen210, which was probably due to the fact that HMR is a nuclear/plastidial dual-localized protein, and its strong plastid transit peptide limits the abundance of HMR proteins in the nucleus (Chen et al., 2010; Nevarez et al., 2017). Taken together, the results from the GST pull-down assays and the BiFC assays indicate that MED14 may be physically associated with PIF4 and HMR.

\section{The association of MED14 with thermo-induced genes requires PIF4 and HMR}

To elucidate the molecular mechanisms by which PIF4 and HMR recruit MED14 to the thermoresponsive PIF4 targets for transcriptional activation, we compared the association of MED14 with representative PIF4 targets in the presence and absence of functional PIF4 or HMR using ChIP-qPCR assays. The 35S::MED14-HA/med14 transgenic lines were crossed with pif4-2 and $h m r-22$, respectively. The homozygous F3 progenies of MED14-HA/pif4-2 and MED14$H A / h m r-22$ were used to compare MED14 occupancy across IAA29 and IAA19, two PIF4/HMR/MED14-dependent thermoresponsive PIF4 direct targets, with that in MED14-HA after a 6-hour warm temperature treatment. The ChIP-qPCR results showed that MED14-HA is highly associated with the G-box (CACGTG)-containing regions in both IAA29 and IAA19, confirming the physical presence of MED14 in the promoters of these two PIF4 targets (Supplemental Figure S4). Interestingly, this association was significantly reduced at the G-boxcontaining regions in the pif4-2 or hmr-22 mutant background (Figure 5A-D). We further crossed MED14-HA/hmr-22 with $r c b$-101, a suppressor of hmr-22 that can rescue hmr-22's defects in thermomorphogenetic PIF4 activity and protein stability (Qiu et al., 2021). The association of MED14 with the G-box-containing regions in both IAA29 and IAA19 were rescued in the MED14-HA/hmr-22/rcb-101 seedlings (Figure 5C, D). These data indicate that MED14 may be 


\section{Discussion}

Transcriptional regulation of thermoresponsive genes is one of the earliest and principal steps in plant thermomorphogenesis. We previously discovered that PIF4 and its coactivator HMR promote thermomorphogenetic hypocotyl growth in the daytime by activating the transcription of key growth-promoting genes (Qiu et al., 2019; Qiu et al., 2021). In this study, we further demonstrate that PIF4/HMR-mediated transcriptional regulation is achieved by recruiting the Mediator complex through their direct interactions with MED14 (Figure 5E).

The Mediator complex is required for virtually all Pol II-mediated transcription in eukaryotes (Jeronimo and Robert, 2017; Soutourina, 2018). As a crucial component of the Mediator complex, MED14 has long been known to play important roles in the transcription of key genes involved in various developmental processes and stress responses, including cell proliferation, shoot apical meristem development, trichome papillae development, salicylic acid-, methyl jasmonate-, and ethylene-mediated plant immune responses, abscisic acid-dependent drought responses, as well as cold and heat stress responses (Autran et al., 2002; Zhang et al., 2013; Hemsley et al., 2014; Wang et al., 2016; Fornero et al., 2019; Ohama et al., 2020; Lee et al., 2021a). In particular, MED14 works with MED16 and MED2 in modulating cold-responsive genes regulated by the AP2 transcription factors $\mathrm{C}$-repeat binding factors ( $\mathrm{CBFs}$ ), and operates with MED17 in activating heat stress-inducible genes by assisting HsfA1, a heat shock transcription factor (HSF) that functions as a master regulator of the heat stress response (Hemsley et al., 2014; Ohama et al., 2020). We show here that MED14's function is not limited to plant responses to extreme cold or hot temperatures, rather, it is also indispensable for the transcription of growth-related genes involved in moderately elevated temperature responses (Figure 1-3).

In higher eukaryotes, Mediator contains at least 7 tail components, namely MED2/29/32, MED3/27, MED5/24/33, MED15, MED16, MED23, and MED25 (Buendía-Monreal and Gillmor, 2016; Dolan and Chapple, 2017; Soutourina, 2018). Although originally assigned to the tail module (Dotson et al., 2000), MED14 was later found to play a more complex and critical role in both basal and activated transcription. For example, the cryo-electron microscopy (CryoEM) structure of Schizosaccharomyces pombe Mediator revealed that yeast MED14 functions as a backbone that connects the head, middle, and tail modules (Tsai et al., 2017). Likewise, Mus musculus MED14 is also centrally positioned, which enables inter-module interactions and makes it heavily involved in tail interactions (Zhao et al., 2021). Although it has not been definitively determined, Arabidopsis MED14 may possess similar structural features and play equally important roles in bridging all three modules as well as interacting with specific transcription factors, as suggested here by our data showing that MED14 physically interacts with activators PIF4 and HMR for thermoresponsive gene expression (Figure 4). 
325 Nevertheless, the precise molecular details underlying the PIF4/HMR-MED14 interaction and

326 the subsequent transcriptional activation of thermo-induced genes have yet to be revealed.

327 Recent studies revealed that a variety of mammalian and yeast transcription factors form phase-

328 separated condensates with Mediator through diverse TADs and that the formation of such

329 condensates is associated with gene activation (Boija et al., 2018; Sabari et al., 2018). The phase-

330 separating capacity of TADs and Mediator subunits is endowed by intrinsically disordered

331 regions (IDRs), low-complexity protein segments that lack a defined secondary structure. In

332 most eukaryotes, more than $80 \%$ of transcription factors and $75 \%$ of Mediator subunits possess

333 extended ( $\geq 30$ residues) IDRs (Liu et al., 2006; Tóth-Petróczy et al., 2008). Similarly, numerous

334 plant transcription factors and Mediator subunits are predicted to contain at least one IDR

335 (Nagulapalli et al., 2016; Salladini et al., 2020). In particular, the bHLH transcription factor

336 family, to which PIF4 belongs, is hypothesized to have a general ability to undergo spontaneous

337 liquid-liquid phase separation in transcription regulation by their IDRs (Tarczewska and Greb-

338 Markiewicz, 2019; Salladini et al., 2020). Both PIF4 and HMR possess TADs that are potentially

339 intrinsically disordered and thus could contribute to interactions with the Mediator complex.

340 PIF4's TAD contains a variant of the $\Phi x x \Phi \Phi$ motif ( $\Phi$ indicates a bulky hydrophobic residue

341 and $\mathrm{x}$ is any other amino acid) flanked by multiple acidic residues, a structural feature that

342 resembles the activator motifs in other activators such as mammalian p53 and yeast Gcn4 (Yoo

343 et al., 2021). Mutating the $\Phi \times x \Phi \Phi$ motif reduced PIF4 transcriptional activity in yeast (Yoo et

344 al., 2021). HMR possesses an acidic type 9aaTAD, the mutation of which drastically reduces its

345 transactivation activity (Qiu et al., 2015) and affects MED14 recruitment to the promoter of

346 PIF4-regulated thermo-induced genes (Figure 5). Future research will focus on unraveling the

347 interaction mechanism between PIF4/HMR and MED14. 


\section{Methods}

Plant materials and growth conditions

All the Arabidopsis mutants used in this study are in the Col-0 background. Mediator mutants were obtained from the Arabidopsis Biological Resource Center and the detailed list is shown in Supplemental Table S1. Homozygosity was confirmed by PCR before the seeds were used for phenotyping. Other Arabidopsis mutants, including pif4-2 (SAIL_1288_E07) and hmr-22, were previously described (Leivar et al., 2008; Qiu et al., 2015; Qiu et al., 2019). Seeds were briefly rinsed with $70 \%$ ethanol and surface sterilized with bleach (3\% sodium hypochlorite) for 10 min before being plated on half-strength Murashige and Skoog (1/2 MS) media supplemented with Gamborg's vitamins (MSP0506, Caisson Laboratories, North Logan, UT), 0.5 mM MES (pH 5.7), and $0.8 \%$ (w/v) agar (A038, Caisson Laboratories, North Logan, UT). Seeds were stratified in the dark at $4{ }^{\circ} \mathrm{C}$ for 3-5 days to synchronize germination before treatment under specific light and temperature conditions in LED chambers (Percival Scientific, Perry, IA). Fluence rates of light were measured using an Apogee PS200 spectroradiometer (Apogee Instruments Inc., Logan, UT).

\section{Hypocotyl measurements}

Seedlings were grown at either $20^{\circ} \mathrm{C}$ or $27^{\circ} \mathrm{C}$ under continuous $\mathrm{R}$ light $\left(50 \mu \mathrm{mol} \mathrm{m} \mathrm{s}^{-2}\right)$ for 96 hours. More than thirty seedlings from each line were placed on transparency film paper and scanned using an Epson Perfection V700 photo scanner. Hypocotyl length was measured using NIH ImageJ software (http://rsb.info.nih.gov/nih-image/). The percent increase in the hypocotyl length of each line was calculated as the percentage of the increase in hypocotyl length at $27^{\circ} \mathrm{C}$ compared with that at $20{ }^{\circ} \mathrm{C}$. The relative response of a mutant is defined as the percentage of its PI value or temperature response relative to that of Col-0. At least three replicates were used to calculate the mean and standard deviation of each relative response. Violin and box plots were generated using Prism 9 (GraphPad Software, San Diego, CA).

\section{Plasmid constructions}

All PCR reactions were performed using the Q5 High-Fidelity DNA Polymerase and the ligation reactions with the NEBuilder HiFi DNA Assembly Master Mix (New England Biolabs Inc., Ipswich, MA). To generate the binary vector for making MED14 transgenic lines, the full-length coding sequence (CDS) of $M E D 14$ was fused with the sequence of a $(P T)_{4} P$ linker and 3 copies of an HA-tag when being cloned into the binary vector pCHF1 between SacI and BamHI. The bait vectors used in GST pull-down assays were either made previously (Qiu et al., 2015) or generated by cloning the full-length CDS of PIF4 into pET42b vectors between BamHI and HindIII, and prey vectors were constructed by cloning the full-length CDS of MED14 into the pCMX-PL2-NterHA vector between EcoRI and BamHI. Vectors used for the Bimolecular 
cloning the full-length CDS of MED14 into MCS III between KfII and AatII. All the primers used for plasmid constructions are listed in Supplemental Table S2.

\section{Generation of transgenic lines}

To generate the $35 S:: M E D 14-H A / m e d 14$ transgenic lines, the med14 mutant was transformed with the above-described $p C H F 1-M E D 14-(P T)_{4} P-3 \times H A$ plasmid using the Agrobacteriummediated floral dip method. The transformants were selected on the 1/2 MS medium containing $100 \mu \mathrm{g} / \mathrm{ml}$ gentamycin. At least 10 independent lines that segregated approximately $3: 1$ for gentamycin-resistance in the T2 generation were identified and two of these lines were selected for this study on the basis of the transgene expression level. For all experiments, T3 selfprogenies of homozygous T2 plants were used.

$R N A$ extraction and quantitative reverse transcription $P C R(R T-q P C R)$

Total RNA was extracted from 50-100 mg seedlings using the Quick-RNA Miniprep Kit with on-column DNase I digestion (Zymo Research, Irvine, CA). cDNA was synthesized with 2-2.5 $\mu \mathrm{g}$ total RNA using the Invitrogen SuperScript III Reverse Transcriptase and the Oligo $(\mathrm{dT})_{20}$ primer (Thermo Fisher Scientific, Waltham, MA). For RT-qPCR, cDNA diluted in nuclease-free water was mixed with FastStart Universal SYBR Green Master (MilliporeSigma, Burlington, MA) and gene-specific primers (Supplemental Table S3). RT-qPCR reactions were performed in triplicate with a Qiagen Rotor-Gene Q 5Plex real-time cycler (Qiagen, Germantown, MD). Transcript levels of each gene were calculated relative to that of $P P 2 A$. A standard curve was performed for each gene to determine the linear range, efficiency, and reproducibility of the qPCR assay. Bar charts were generated using Prism 9 (GraphPad Software, San Diego, CA).

\section{RNA-seq and data analysis}

RNA was isolated as described above. The RNA concentration and purity were determined spectrophotometrically using the Nanodrop 2000 instrument (Thermo Fisher Scientific, Waltham, MA), and assessing the continuous spectrum (190 nm to $840 \mathrm{~nm}$ ) generated by the instrument for each sample. The quality of the RNA samples was evaluated on the Agilent 2100 Bioanalyzer (Agilent Technologies Inc., Santa Clara, CA).

Sequencing libraries were generated with $300 \mathrm{ng}$ to $1 \mu \mathrm{g}$ of RNA using the TruSeq Stranded mRNA Sample Preparation Kit (Illumina, San Diego, CA). The libraries were assessed for size and purity using the Agilent 2100 Bioanalyzer and quantitated by qPCR using a KAPA Biosystems Library Quantitation kit (Roche, Pleasanton, CA). Libraries were normalized, pooled, and diluted to a loading concentration of $1.8 \mathrm{pM}$, loaded on an Illumina High-Output Flow Cell, and sequenced on the Illumina NextSeq 500 instrument. The sequencing run generated $\sim 16$ million 150 bp paired-end reads per sample, and all run metrics, including QScore distributions, cluster densities, and total sequence yields, were within the recommended parameters. 
Data analysis was performed using the Qiagen CLC Genomics Workbench (CLCGWB) version 21 software. The reads were mapped to the A. thaliana reference genome (TAIR10/Araport11 genome release), using default parameters with a strand-specific alignment protocol. The mapping report indicated that all metrics fell within the recommended parameters, with $>90 \%$ of the reads per sample mapping to the reference genome. The mapping results generated values for Total Counts, Transcripts per Million reads, as well as Fragments Per Kilobase of exon per Million reads mapped (FPKM) for each gene. The "Differential Expression for RNA-Seq" tool in CLCGWB software was used, with default parameters, to identify differentially expressed genes across samples. Genes that had a fold-change of $\geq 2$, an FDR-corrected p-value of $<0.001$, and a Maximum Group Mean FPKM of $>1$ (i.e., the maximum of the average FPKM across the two groups in each statistical comparison) were considered to be significantly differentially expressed. The list of differentially expressed genes obtained in each statistical comparison is shown in Supplemental Dataset 1. Venn diagrams were generated using the Bioinformatics and Evolutionary Genomics website (https://bioinformatics.psb.ugent.be/webtools/Venn/). Hierarchical cluster analysis was performed with the Morpheus software tool available at the Broad Institute website (https://software.broadinstitute.org/morpheus/). Gene Ontology (GO) enrichment analyses were performed using the PANTHER classification tool available at the TAIR website (https://www.arabidopsis.org/tools/go_term_enrichment.jsp) or the GeneCodis 4 program (https://genecodis.genyo.es/) (García-Moreno et al., 2021). For comparison of data with published datasets, the appropriate FastQ files available in the NCBI-GEO database were imported into CLCGWB software, and all analyses were conducted in a similar manner to those described above. For the published datasets that utilized a 3'TagSeq protocol, mapping was performed using the 3'-Sequencing option in the CLCGWB alignment parameters.

RNA-Seq data accession number. The RNA-Seq analysis data described in this article are accessible through accession no. GSE196969 at NCBI's Gene Expression Omnibus database.

Protein extraction and immunoblots

458 For immunoblots, total protein was extracted from 4-day-old seedlings as previously described (Qiu et al., 2019; Qiu et al., 2021). Briefly, $200 \mathrm{mg}$ seedlings were freshly homogenized using a BeadBug microtube homogenizer (Benchmark Scientific Inc., Sayreville, NJ) in three volumes $(\mathrm{mg} / \mu \mathrm{L})$ of extraction buffer containing $100 \mathrm{mM}$ Tris-HCl pH 7.5, $100 \mathrm{mM} \mathrm{NaCl}, 5 \mathrm{mM}$ EDTA, 5\% SDS, 20\% glycerol, $20 \mathrm{mM}$ DTT, $40 \mathrm{mM} \beta$-mercaptoethanol, $2 \mathrm{mM}$ phenylmethylsulfonyl fluoride, $40 \mu \mathrm{M}$ MG115 (Apexbio Technology LLC, Houston, TX), $40 \mu \mathrm{M}$ MG132 (Cayman Chemical, Ann Arbor, MI), $40 \mu \mathrm{M}$ bortezomib (MilliporeSigma, Burlington, MA), $10 \mathrm{mM}$ Nethylmaleimide (Thermo Fisher Scientific, Waltham, MA), 1× phosphatase inhibitor cocktail 2 
and $0.01 \%$ bromophenol blue. Samples were boiled for $10 \mathrm{~min}$ and centrifuged at $16,000 \times \mathrm{g}$ for $10 \mathrm{~min}$. The supernatant was immediately used for immunoblots or stored at $-80{ }^{\circ} \mathrm{C}$ until use.

For immunoblots, cleared protein samples were separated via SDS-PAGE, transferred to nitrocellulose membranes, probed with the indicated primary antibodies, and then incubated with 1:5000 dilution of horseradish peroxidase-conjugated goat anti-rabbit or anti-mouse secondary antibodies (Bio-Rad Laboratories, 1706515 for anti-rabbit and 1706516 for anti-mouse). Primary antibodies, including monoclonal mouse anti-HA antibodies (MilliporeSigma, H3663), polyclonal rabbit anti-HMR antibodies (Chen et al., 2010), polyclonal goat anti-PIF4 antibodies (Agrisera, AS16 3955), and polyclonal rabbit anti-RPN6 antibodies (Enzo Life Sciences, BMLPW8370-0100) were used at 1:1000 dilution. Signals were detected via chemiluminescence using a SuperSignal kit (Thermo Fisher Scientific, Waltham, MA) and an Azure C600 Advanced Imaging System (Azure Biosystems, Dublin, CA).

\section{Chromatin immunoprecipitation}

ChIP assays were performed as previously described with modifications (Wu et al., 2016). Seedlings grown on $1 / 2 \mathrm{MS}$ medium in continuous red light $\left(50 \mu \mathrm{mol} \mathrm{m} \mathrm{m}^{-2}\right)$ at $20^{\circ} \mathrm{C}$ for $96 \mathrm{~h}$ were treated at $27^{\circ} \mathrm{C}$ for $6 \mathrm{~h}$ before collecting. About $200 \mathrm{mg}$ seedlings were cross-linked with $1 \%$ formaldehyde in $1 \times$ PBS for $2 \times 15$ min by vacuum infiltration, followed by the addition of glycine to $125 \mathrm{mM}$ with another $10 \mathrm{~min}$ of vacuum infiltration. Fixed seedlings were dried on a stack of paper towels after being washed with $4 \times 10 \mathrm{ml}$ cold PBS. Samples were ground into a fine powder in liquid nitrogen and resuspended in Nuclear Isolation Buffer $(20 \mathrm{mM}$ Hepes, $\mathrm{pH}$ 7.6, $0.25 \mathrm{M}$ sucrose, $5 \mathrm{mM} \mathrm{KCl,} 10 \mathrm{mM} \mathrm{MgCl}_{2}$, 40\% glycerol, $0.25 \%$ Triton $\mathrm{X}-100,0.1 \mathrm{mM}$ PMSF, $0.1 \% \beta$-mercaptoethanol, $1 \times$ complete EDTA-free protease inhibitor cocktail (MilliporeSigma, Burlington, MA). Nuclei were enriched by filtering the lysate through two layers of Miracloth and centrifugation at 3,000 $\times \mathrm{g}$ for $10 \mathrm{~min}$ at $4{ }^{\circ} \mathrm{C}$. Nuclear pellets were resuspended in Nuclei Lysis Buffer (20 mM Tris-HCl, pH 7.5, $100 \mathrm{mM} \mathrm{NaCl,} 2.5 \mathrm{mM}$ EDTA, $10 \%$ glycerol, $1 \%$ Triton X-100, $1 \times$ protease inhibitor cocktail) and sonicated with 25 cycles of 30-s-long pulses (30-s intervals) using a Bioruptor Plus (Diagenode, Denville, NJ). Nuclear lysates were cleared with 2 rounds of centrifugation at $13,000 \times \mathrm{g}$ for $5 \mathrm{~min}$ at $4{ }^{\circ} \mathrm{C}$. Immunoprecipitation was performed by incubating $30 \mu \mathrm{L}$ of Dynabeads Protein $\mathrm{G}$ (Thermo Fisher Scientific, Waltham, MA), $2.5 \mu \mathrm{g}$ of anti-HA tag antibody (Abcam, Waltham, MA), and 1 $\mathrm{mL}$ of diluted chromatin (containing $100 \mu \mathrm{L}$ of sonicated chromatin) at $4{ }^{\circ} \mathrm{C}$ for $4 \mathrm{~h}$. Beads were washed for $2 \times 15 \mathrm{~min}$ with low-salt wash buffer $(20 \mathrm{mM}$ Tris- $\mathrm{HCl}, \mathrm{pH} 7.5,150 \mathrm{mM} \mathrm{NaCl}, 2.5$ mM EDTA, $0.05 \%$ SDS, $1 \%$ Triton X-100), for $2 \times 15$ min with high-salt wash buffer (20 mM Tris- $\mathrm{HCl}, \mathrm{pH} 7.5,500 \mathrm{mM} \mathrm{NaCl}, 2.5 \mathrm{mM}$ EDTA, $0.05 \%$ SDS, $1 \%$ Triton $\mathrm{X}-100$ ), for $1 \times 15 \mathrm{~min}$ with LiCl Wash Buffer (20 mM Tris-HCl, pH 7.5, $250 \mathrm{mM} \mathrm{LiCl,} 1 \mathrm{mM}$ EDTA, 0.5\% Nadeoxycholate, $0.5 \%$ Nonidet P-40), and for $1 \times 15$ min with TE buffer (10 mM Tris-HCl, $\mathrm{pH} 7.5$, $1 \mathrm{mM}$ EDTA). $10 \%$ (wt/vol) chelex resin (Bio-Rad, Hercules, CA) was mixed with the beads and immunoprecipitated DNA was eluted after reverse cross-linking by boiling at $95{ }^{\circ} \mathrm{C}$ for 10 
min, followed by treatment with $40 \mu \mathrm{g}$ of proteinase $\mathrm{K}$ for $1 \mathrm{~h}$ at $55^{\circ} \mathrm{C}$. Eluted DNA was recovered using the ChIP DNA Clean \& Concentrator kit (Zymo Research, Irvine, CA) and used for qPCR reactions. Primers for ChIP-qPCR are listed in Supplemental Table S4. Values are means \pm SD from two independent samples; data are presented as a ratio of (MED14-HA IAA/input IAA) to (MED14-HA at internal control/input at internal control) to correct for tube-totube variation (the MED14-HA level at position +1912 in Actin7 was used as an internal control for normalization).

GST pull-down

GST pull-down assays were performed as described previously (Qiu et al., 2015; Qiu et al., 2021). The pET42b/PIF4 and pET42b/HMR vectors were constructed as described above and expressed as GST-PIF4 and GST-HMR fusion proteins in the E. coli strain BL21-CodonPlus (DE3) (Agilent Technologies). The pCMX-PL2-NterHA/MED14 vector was constructed as described above and expressed as HA-MED14 proteins using the TNT T7 Coupled Reticulocyte Lysate System (Promega, Madison, WI). HA-MED14 prey proteins were incubated with the affinity-purified GST-PIF4 or GST-HMR bait proteins immobilized on glutathione Sepharose 4B beads (GE Healthcare, Chicago, IL) at $4{ }^{\circ} \mathrm{C}$ for $2 \mathrm{~h}$. Beads were washed four times with E buffer (50 mM Tris-HCl, pH 7.5, 100 mM NaCl, 1 mM EDTA, 1 mM EGTA, 1\% DMSO, 2 mM DTT, $0.1 \%$ Nonidet P-40). Bound proteins were eluted by boiling in $2 \times$ SDS loading buffer and used in subsequent SDS-PAGE and immunoblotting. Input and immunoprecipitated HA-MED14 prey proteins were detected using goat anti-HA polyclonal antibodies (GenScript, Piscataway, NJ). The amounts of GST-PIF4 and GST-HMR bait proteins were visualized by staining the SDSPAGE with Coomassie Brilliant Blue.

\section{Agroinfiltration-based Bimolecular fluorescence complementation (BiFC)} The pDOE-01/PIF4 and pDOE-01/PIF4/MED14 vectors were constructed as shown above. The BiFC assays were performed as described (Gookin and Assmann, 2014). The constructed pDOE01 vectors were transformed into GV3101 Agrobacterium electrocompetent cells and selected on $25 \mu \mathrm{g} / \mathrm{ml}$ rifampicin, $20 \mu \mathrm{g} / \mathrm{ml}$ gentamycin, and $50 \mu \mathrm{g} / \mathrm{ml}$ kanamycin at $29{ }^{\circ} \mathrm{C}$ for $2-3$ days. Several colonies of positive transformants were harvested from the plate, inoculated to LB media containing the above-mentioned antibiotics, and cultured at $29{ }^{\circ} \mathrm{C}$ for $2 \mathrm{~h}$ with $100 \mu \mathrm{M}$ acetosyringone (MilliporeSigma, Burlington, MA). The Agrobacterium cells were washed with and diluted to an $\mathrm{OD}_{600}$ of 0.03 in the infiltration buffer $(10 \mathrm{mM}$ MES-KOH, pH 5.6, $10 \mathrm{mM}$

Nicotiana benthamiana plants were grown in General Purpose Pro-Mix BX (Premier Tech $\mathrm{MgCl}_{2}$, and $100 \mu \mathrm{M}$ acetosyringone).

Horticulture, Quakertown, PA) in a growth room with $150 \mu \mathrm{mol} / \mathrm{m}^{2} / \mathrm{sec}$ white light, 14-h light/10-h dark cycles, and a temperature range between $21-24{ }^{\circ} \mathrm{C}$. BiFC control and test infiltrations were performed on three plants each. Fluorescence signals were examined 48-72 hours after agroinfiltration using a Leica SP8 Inverted Confocal Microscope (Leica 
Microsystems Inc., Buffalo Grove, IL). Excitation and emission wavelengths for mVenus were $488 \mathrm{~nm}$ and 500-550 nm, respectively.

\section{Accession Numbers}

552 Accession numbers are as described by TAIR (https://www.arabidopsis.org) as follows:

553 PHYTOCHROME-INTERACTING FACTOR 4 (PIF4), AT2G43010; HEMERA (HMR), AT2G34640; MED2/29/32, AT1G11760; MED3/27, AT3G09180; MED5A/33A, AT3G23590; MED5B/33B, AT2G48110; MED6, AT3G21350; MED7A, AT5G03220; MED7B, AT5G03500; MED8, AT2G03070; MED9, AT1G55080; MED10A, AT5G41910; MED10B, AT1G26665; MED14, AT3G04740; MED16, AT4G04920; MED17, AT5G20170; MED18, AT2G22370; MED19A, AT5G12230; MED22A, AT1G16430; MED22B, AT1G07950; MED23, AT1G23230; MED25, AT1G25540; MED28, AT3G52860; MED30, AT5G63480; MED31, AT5G19910; CYCLINC1-2 (CYCCA), AT5G48630; CYCLINC1-1 (CYCCB), AT5G48640; SERINE/THREONINE PROTEIN PHOSPHATASE 2A (PP2A), AT1G69960; YUCCA8 (YUC8), AT4G28720; INDOLE-3-ACETIC ACID INDUCIBLE 19 (IAA19), AT3G15540; INDOLE-3-ACETIC ACID INDUCIBLE 29 (IAA29), AT4G32280; SULFOTRANSFERASE 2A (ST2A), AT5G07010; ARABIDOPSIS PP2C CLADE D 7 (APD7), AT5G02760; AUXINREGULATED GENE INVOLVED IN ORGAN SIZE (ARGOS), AT3G59900; RING, AT1G24580; SERINE CARBOXYPEPTIDASE-LIKE 31 (SCPL31), AT1G11080; METHYL ESTERASE 18 (MES18), AT5G58310; ACTIN 7 (ACT7), AT5G09810.

\section{Supplemental Data} Supplemental Figure S2. Comparison of thermoresponsive transcriptomes in wild-type seedlings from different studies. temperatures.

578 Supplemental Table S3. RT-qPCR primers for the genes examined in this study.

579 Supplemental Table S4. ChIP-qPCR primers for the genes examined in this study.

580 Supplemental Dataset 1: Lists of SSTF genes regulated by warm temperatures in Col-0, pif4-2, $581 \quad h m r-22$, and med14.

582 Supplemental Dataset 2: Lists of thermo-responsive genes in two other reports.

583 Supplemental Dataset 3: Lists of PIF4/HMR/MED14-dependent thermo-responsive genes.

584 Supplemental Dataset 4: Lists of potential PIF4/HMR/MED14-dependent, thermo-responsive 585 PIF4 direct targets.

\section{Data Availability Statement}


The original contributions presented in the study are included in the article/Supplementary this study can be found in online repositories. The names of the repository/repositories and accession number(s) can be found at NCBI's Gene Expression Omnibus database (https://www.ncbi.nlm.nih.gov/geo/), GSE196969.

\section{Funding}

This work was supported by a grant from the National Science Foundation (NSF) (IOS-2200200) and startup funds from the University of Mississippi (Oxford, MS) to Y.Q. The early stages of these studies were performed in Meng Chen laboratory at the University of California at Riverside, with funding from the National Institute of General Medical Sciences (NIGMS) of the National Institutes of Health (NIH) (R01GM087388) to M.C. The work related to the confocal microscope was supported by an Institutional Development Award (IDeA) from NIGMS of the NIH under award number P20GM103460 to the Imaging Research Core of the Glycoscience Center of Research Excellence (GlyCORE) at the University of Mississippi.

\section{Acknowledgments}

We would like to thank Dr. Gregg Roman and Dr. Ruofan Cao in the Imaging Research Core of GlyCORE at the University of Mississippi for their assistance with the usage of the Leica SP8 Inverted Confocal Microscope. We also thank all the lab members, especially Ranjeeta Odari and Anupa Wasti, for their critical comments and suggestions regarding the manuscript.

\section{Author Contributions} experiments; AB, JX, KFG, EEB, CAG, CHC, AKA, and YQ performed the experiments; AB, JX, SRB, AKA, and YQ analyzed the data; YQ wrote the article with the contributions from all authors; all authors approved the submitted version.

\section{Conflict of Interest Statement}

\section{Figure Legends}

\section{Figure 1. MED14 is a crucial regulator of thermomorphogenesis.} components in the tail module. The size of each circle reflects the relative protein size (predicted molecular weight) of each mediator subunit. The relative position of each mediator component is based on the cryo-EM and crystal structures of yeast and human Mediator (Tsai et al., 2014; Robinson et al., 2015) and interaction data of Arabidopsis mediator subunits (Maji et al., 2019). Note that the positions of MED23 and MED25 in the tail module are undetermined. Protein 
subunits in each module are colored in different colors: head module, green; middle module, blue; tail module, orange; cyclin kinase module, purple. See Supplemental Figure S1 for clear compositions of each module.

(B) Hypocotyl length measurements of mutant seedlings of mediator tail subunits. The white and grey bars represent hypocotyl length measurements at $20^{\circ} \mathrm{C}$ and $27^{\circ} \mathrm{C}$, respectively. The results of the one-way ANOVA analysis comparing the absolute hypocotyl length between Col-0 and each mutant grown at $27^{\circ} \mathrm{C}$ are shown $(\mathrm{n}>30) .{ }^{* * * *}, p<0.0001 ;^{* * *}, p<0.001 ;{ }^{* *}, p<0.01 ;^{*}, p$ $<0.05$; ns, not significant $(p \geq 0.05)$.

(C) Comparison of the relative thermal response among the seedlings in (B). The relative response is defined as the relative hypocotyl response to $27{ }^{\circ} \mathrm{C}$ of a mutant compared with that of Col-0 (which is set at 100\%). The results of the one-way ANOVA analysis comparing the relative response between Col-0 and each mutant are shown $(\mathrm{n} \geq 3){ }^{* * * *}, p<0.0001 ;^{* * *}, p<$ $0.001 ;^{* *}, p<0.01 ;^{*}, p<0.05$; ns, not significant $(p \geq 0.05)$.

(D) Representative images of 4-d-old Col-0, med14, and 35S::MED14-HA/med14 (\#20 and \#25) seedlings at either $20^{\circ} \mathrm{C}$ or $27^{\circ} \mathrm{C}$.

644

(E) Hypocotyl length measurements of seedlings in (D). Different letters denote significant statistical differences between the absolute hypocotyl length of each line grown at $27{ }^{\circ} \mathrm{C}$ (oneway ANOVA, $\mathrm{n}>30, p<0.0001)$.

(F) Comparison of the relative thermal response among the seedlings in (D). Different letters denote significant statistical differences between the relative response of each line (one-way ANOVA, $\mathrm{n} \geq 4, p<0.0001)$.

Figure 2. MED14 is required for the thermo-induced expression of PIF4 target genes. (A) RT-qPCR analysis of the steady-state transcript levels of YUC8, IAA19, IAA29, PIF4, and $H M R$ in Col-0 and med14 seedlings grown in $\mathrm{R}$ light for $96 \mathrm{~h}$ at $20^{\circ} \mathrm{C}$ and $27{ }^{\circ} \mathrm{C}$. Numbers indicate the fold changes between transcript levels at these two temperatures. (B) RT-qPCR analysis of the steady-state transcript levels of YUC8, IAA19, IAA29, PIF4, and $H M R$ in Col- 0 and med 14 during the $21{ }^{\circ} \mathrm{C}$-to- $27{ }^{\circ} \mathrm{C}$ transitions. Seedlings were grown in $\mathrm{R}$ light for $96 \mathrm{~h}$ and then transferred to $27{ }^{\circ} \mathrm{C}$ in the same light condition. Samples were taken before (light grey) and $6 \mathrm{~h}$ after (dark grey) the $27^{\circ} \mathrm{C}$ treatment. Fold changes in the transcript levels by the $27^{\circ} \mathrm{C}$ treatment are shown above the columns. For (A) and (B), transcript levels were calculated relative to those of $P P 2 A$. Error bars represent the SD of three technical replicates. (C) Immunoblot analysis of HMR and PIF4 levels in Col-0 and med14 during the $21^{\circ} \mathrm{C}$-to-27 ${ }^{\circ} \mathrm{C}$ transitions. Seedlings were grown in R light for $96 \mathrm{~h}$ and then transferred to $27{ }^{\circ} \mathrm{C}$ in the same light condition. Samples were collected and analyzed at the indicated time points. RPN6 was used as a loading control. The relative levels of HMR and PIF4, normalized to RPN6, are shown underneath the immunoblots. The results of the student t-test analysis are shown $(\mathrm{n}=3$ or 4$) .{ }^{*}, p$ $<0.05$; ns, not significant $(p \geq 0.05)$. 
667 Figure 3. Thermo-induced expression of a group of auxin-related, growth-promoting genes requires PIF4, HMR, and MED14.

669 (A) A Venn diagram shows unique and co-regulated thermo-induced and thermo-repressed genes in wild type (Col-0), pif4-2, hmr-22, and med14 mutants. The red circles indicate PIF4/HMR/MED14-dependent genes that were uniquely induced and repressed in Col-0 but not in the mutants at $27{ }^{\circ} \mathrm{C}$. Seedlings were grown in continuous red light for $96 \mathrm{~h}$ at either $20{ }^{\circ} \mathrm{C}$ or $27{ }^{\circ} \mathrm{C}$, and total RNA was extracted from four biological replicates for RNA-seq analyses.

(B) Gene ontology analysis of the 324 PIF4/HMR/MED14-dependent thermo-induced genes and 281 PIF4/HMR/MED14-dependent thermo-repressed genes. The bar represents the fold enrichment and the color indicates the -log10(p-value). ACC, 1-aminocyclopropane-1carboxylate (an ethylene precursor). ppGpp, guanosine tetraphosphate.

678 (C,D) RT-qPCR analysis of representative PIF4/HMR/MED14-dependent genes in Col-0, pif4-2, $h m r-22$, and med14. Total RNA was extracted from seedlings grown in continuous red light for $96 \mathrm{~h}$ at either $20^{\circ} \mathrm{C}$ or $27^{\circ} \mathrm{C}$. The relative expression of three thermo-induced (C) and three thermo-repressed genes (D) were normalized to the expression level of PP2A after RT-qPCR. Numbers indicate the fold changes between transcript levels at these two temperatures. N.D., not detected. down in vitro translated HA-tagged MED14. The upper panel is an immunoblot using anti-HA antibodies showing the bound and input fractions of HA-MED14; the lower panel is a Coomassie Blue-stained SDS-PAGE gel showing immobilized GST and GST-tagged PIF4 and HMR. (B) Bimolecular fluorescence complementation assays. PIF4 fused with NmVenus210 (PIF4:NmVenus210) and MED14 fused with cVenus210 (MED14:CVenus210) were coexpressed in Nicotiana benthamiana through agroinfiltration. PIF4:NmVenus210 and CVenus 210 were co-expressed as a control. The optical density of each Agrobacterium strain was 0.03 and images were captured $48 \mathrm{~h}$ after infiltration. The fluorescence signal (Venus) in the nucleus indicates the interactions between the two proteins tested in each agroinfiltration. The Chloroplast channel is to show that the Venus signal was not caused by the chlorophyll

Figure 5. The association of MED14 with thermo-induced PIF4 direct targets is dependent on PIF4 and HMR.

702 ChIP-qPCR experiments compare MED14 occupancy across IAA29 (A and C) or IAA19 (B and D) in the presence and absence of functional PIF4 (A and B) or HMR (C and D). Four-day-old $20{ }^{\circ} \mathrm{C}$-grown MED14-HA, MED14-HA/pif4-2, MED14-HA/hmr-22, and MED14-HA/hmr$22 / r c b$ - 101 were treated at $27{ }^{\circ} \mathrm{C}$ for 6 hours. HA antibody was used to assay MED14-HA association with each gene. Values are mean \pm SD from two independent samples, with data presented as the ratio of MED14-HA at IAA/input to MED14-HA at ACT7 (+1912)/input. 
707 Student $\mathrm{t}$-tests were used to compare the values between MED14-HA and other lines. ${ }^{* * * *}, p<$

$7080.0001 ;^{* * *}, p<0.001 ;^{* *}, p<0.01 ;{ }^{*}, p<0.05$; ns, not significant $(p \geq 0.05)$. The exact position

709 of each PCR fragment is shown in the illustrations at the bottom and the primers are listed in

710 Supplemental Table S4. The transcription start site (TSS) is the first nucleotide of the 5'UTR, as

711 defined by the Araport11 genome annotation, released June 2016. (E) Schematic model for

712 MED14 recruitment by PIF4 and HMR during the thermo-induced transcription of growth-

713 promoting PIF4 target genes, the products of which subsequently promote thermosensory

714 hypocotyl elongation. Pol II, RNA polymerase II; GTF, general transcription factors. The black

715 arrow indicates the TSS. The size and proportions of the depicted components do not reflect their

716 actual dimensions. 


\section{References}

722

723

724

725

726

727

728

729

730

731

732

733

734

735

736

737

738

739

740

741

742

743

744

745

746

747

748

749

750

751

752

753

754

755

Autran D, Jonak C, Belcram K, Beemster GTS, Kronenberger J, Grandjean O, Inzé D, Traas J (2002) Cell numbers and leaf development in Arabidopsis: a functional analysis of the STRUWWELPETER gene. EMBO J 21: 6036-6049

Boija A, Klein IA, Sabari BR, Dall'Agnese A, Coffey EL, Zamudio AV, Li CH, Shrinivas K, Manteiga JC, Hannett NM, et al (2018) Transcription Factors Activate Genes through the Phase-Separation Capacity of Their Activation Domains. Cell 175: 1842-1855.e16

Bordiya Y, Kim J, Xi Y, Kim D-H, Pyo Y, Zhao B, Zong W, Ricci WA, Zhang X, Sung S (2020) VIL1, a Polycomb-associated protein, modulates high ambient temperature response via H3K27me3 and H2A.Z in Arabidopsis thaliana. bioRxiv 2020.04.29.069484

Borggrefe T, Yue X (2011) Interactions between subunits of the Mediator complex with genespecific transcription factors. Semin Cell Dev Biol 22: 759-768

Bourbon H-M (2008) Comparative genomics supports a deep evolutionary origin for the large, four-module transcriptional mediator complex. Nucleic Acids Res 36: 3993-4008

Box MS, Huang BE, Domijan M, Jaeger KE, Khattak AK, Yoo SJ, Sedivy EL, Jones DM, Hearn TJ, Webb AAR, et al (2015) ELF3 controls thermoresponsive growth in Arabidopsis. Curr Biol 25: 194-199

Buendía-Monreal M, Gillmor CS (2016) Mediator: A key regulator of plant development. Dev Biol 419: 7-18

Casal JJ, Balasubramanian S (2019) Thermomorphogenesis. Annu Rev Plant Biol 70: 321346

Cevher MA, Shi Y, Li D, Chait BT, Malik S, Roeder RG (2014) Reconstitution of active human core Mediator complex reveals a critical role of the MED14 subunit. Nat Struct Mol Biol 21: 1028-1034

Chen M, Galvão RM, Li M, Burger B, Bugea J, Bolado J, Chory J (2010) Arabidopsis HEMERA/pTAC12 initiates photomorphogenesis by phytochromes. Cell 141: 1230-1240

Chen X, Yin X, Li J, Wu Z, Qi Y, Wang X, Liu W, Xu Y (2021) Structures of the human Mediator and Mediator-bound preinitiation complex. Science. doi: 10.1126/science. $\operatorname{abg} 0635$

Cortijo S, Charoensawan V, Brestovitsky A, Buning R, Ravarani C, Rhodes D, van Noort J, Jaeger KE, Wigge PA (2017) Transcriptional Regulation of the Ambient Temperature Response by H2A.Z Nucleosomes and HSF1 Transcription Factors in Arabidopsis. Mol Plant 10: $1258-1273$

Dalton JC, Bätz U, Liu J, Curie GL, Quail PH (2016) A Modified Reverse One-Hybrid Screen Identifies Transcriptional Activation Domains in PHYTOCHROME- 
Ding L, Wang S, Song Z-T, Jiang Y, Han J-J, Lu S-J, Li L, Liu J-X (2018) Two B-Box Domain Proteins, BBX18 and BBX23, Interact with ELF3 and Regulate Thermomorphogenesis in Arabidopsis. Cell Rep 25: 1718-1728.e4

Dolan WL, Chapple C (2017) Conservation and Divergence of Mediator Structure and

Dolan WL, Dilkes BP, Stout JM, Bonawitz ND, Chapple C (2017) Mediator complex subunits MED2, MED5, MED16, and MED23 genetically interact in the regulation of phenylpropanoid biosynthesis. Plant Cell 29: 3269-3285

Jeronimo C, Robert F (2017) The Mediator Complex: At the Nexus of RNA Polymerase II

Dotson MR, Yuan CX, Roeder RG, Myers LC, Gustafsson CM, Jiang YW, Li Y, Kornberg RD, Asturias FJ (2000) Structural organization of yeast and mammalian mediator complexes. Proc Natl Acad Sci U S A 97: 14307-14310

Fornero C, Rickerd T, Kirik V (2019) Papillae formation on Arabidopsis leaf trichomes requires the function of Mediator tail subunits 2, 14, 15a, 16, and 25. Planta 249: 10631071

Franklin KA, Lee SH, Patel D, Kumar SV, Spartz AK, Gu C, Ye S, Yu P, Breen G, Cohen JD, et al (2011) Phytochrome-interacting factor 4 (PIF4) regulates auxin biosynthesis at high temperature. Proc Natl Acad Sci U S A 108: 20231-20235

García-Moreno A, López-Domínguez R, Ramirez-Mena A, Pascual-Montano A, AparicioPuerta E, Hackenberg M, Carmona-Saez P (2021) GeneCodis 4: Expanding the modular enrichment analysis to regulatory elements. bioRxiv 2021.04.15.439962

Gookin TE, Assmann SM (2014) Significant reduction of BiFC non-specific assembly

Han X, Yu H, Yuan R, Yang Y, An F, Qin G (2019) Arabidopsis Transcription Factor TCP5 Controls Plant Thermomorphogenesis by Positively Regulating PIF4 Activity. iScience 15: $611-622$

Hemsley PA, Hurst CH, Kaliyadasa E, Lamb R, Knight MR, De Cothi EA, Steele JF, Knight H (2014) The Arabidopsis mediator complex subunits MED16, MED14, and MED2 regulate mediator and RNA polymerase II recruitment to CBF-responsive coldregulated genes. Plant Cell 26: 465-484 Transcription. Trends Cell Biol 27: 765-783

Jin H, Lin J, Zhu Z (2020) PIF4 and HOOKLESS1 Impinge on Common Transcriptome and Isoform Regulation in Thermomorphogenesis. Plant Commun 1: 100034

Kim S, Hwang G, Kim S, Thi TN, Kim H, Jeong J, Kim J, Kim J, Choi G, Oh E (2020) The 
epidermis coordinates thermoresponsive growth through the phyB-PIF4-auxin pathway. Nat Commun 11: 1053

Koini MA, Alvey L, Allen T, Tilley CA, Harberd NP, Whitelam GC, Franklin KA (2009) High temperature-mediated adaptations in plant architecture require the bHLH transcription factor PIF4. Curr Biol 19: 408-413 Transcription factor PIF4 controls the thermosensory activation of flowering. Nature 484: $242-245$

Lee M, Dominguez-Ferreras A, Kaliyadasa E, Huang W-J, Antony E, Stevenson T, Lehmann S, Schäfer P, Knight MR, Ntoukakis V, et al (2021a) Mediator Subunits MED16, MED14, and MED2 Are Required for Activation of ABRE-Dependent Transcription in Arabidopsis. Front Plant Sci 12: 649720

Lee S, Paik I, Huq E (2020) SPAs promote thermomorphogenesis by regulating the phyB-PIF4 module in Arabidopsis. Development. doi: 10.1242/dev.189233

Lee S, Wang W, Huq E (2021b) Spatial regulation of thermomorphogenesis by HY5 and PIF4 in Arabidopsis. Nat Commun 12: 3656

Lee S, Zhu L, Huq E (2021c) An autoregulatory negative feedback loop controls thermomorphogenesis in Arabidopsis. PLoS Genet 17: e1009595

809 Leivar P, Monte E (2014) PIFs: systems integrators in plant development. Plant Cell 26: 56-78

Leivar P, Monte E, Oka Y, Liu T, Carle C, Castillon A, Huq E, Quail PH (2008) Multiple phytochrome-interacting bHLH transcription factors repress premature seedling photomorphogenesis in darkness. Curr Biol 18: 1815-1823

Leivar P, Quail PH (2011) PIFs: pivotal components in a cellular signaling hub. Trends Plant

Liu H-C, Charng Y-Y (2013) Common and distinct functions of Arabidopsis class A1 and A2 heat shock factors in diverse abiotic stress responses and development. Plant Physiol 163: 276-290

Liu J, Perumal NB, Oldfield CJ, Su EW, Uversky VN, Dunker AK (2006) Intrinsic disorder

Ludwig W, Hayes S, Trenner J, Delker C, Quint M (2021) On the evolution of plant thermomorphogenesis. J Exp Bot. doi: 10.1093/jxb/erab310 with PIF4 to regulate high temperature-mediated hypocotyl elongation in response to blue light. Proc Natl Acad Sci U S A 113: 224-229 
Maji S, Dahiya P, Waseem M, Dwivedi N, Bhat DS, Dar TH, Thakur JK (2019) Interaction map of Arabidopsis Mediator complex expounding its topology. Nucleic Acids Res 47: 3904-3920

Malik S, Roeder RG (2010) The metazoan Mediator co-activator complex as an integrative hub for transcriptional regulation. Nat Rev Genet 11: 761-772

Nagulapalli M, Maji S, Dwivedi N, Dahiya P, Thakur JK (2016) Evolution of disorder in Mediator complex and its functional relevance. Nucleic Acids Res 44: 1591-1612

Nevarez PA, Qiu Y, Inoue H, Yoo CY, Benfey PN, Schnell DJ, Chen M (2017) Mechanism of Dual Targeting of the Phytochrome Signaling Component HEMERA/pTAC12 to Plastids and the Nucleus. Plant Physiol 173: 1953-1966

Nozawa K, Schneider TR, Cramer P (2017) Core Mediator structure at $3.4 \AA$ extends model of transcription initiation complex. Nature 545: 248-251

Ohama N, Moo TL, Chua N-H (2020) Differential requirement of MED14/17 recruitment for activation of heat inducible genes. New Phytol. doi: 10.1111/nph.17119

Oh E, Zhu JY, Wang ZY (2012) Interaction between BZR1 and PIF4 integrates brassinosteroid and environmental responses. Nat. Cell Biol.

Park Y-J, Kim JY, Lee J-H, Han S-H, Park C-M (2021) External and Internal Reshaping of Plant Thermomorphogenesis. Trends Plant Sci 26: 810-821

Park Y-J, Lee H-J, Ha J-H, Kim JY, Park C-M (2017) COP1 conveys warm temperature information to hypocotyl thermomorphogenesis. New Phytol 215: 269-280

Pedmale UV, Huang S-SC, Zander M, Cole BJ, Hetzel J, Ljung K, Reis PAB, Sridevi P, Nito K, Nery JR, et al (2016) Cryptochromes Interact Directly with PIFs to Control Plant Growth in Limiting Blue Light. Cell 164: 233-245

Pfeiffer A, Shi H, Tepperman JM, Zhang Y, Quail PH (2014) Combinatorial complexity in a transcriptionally centered signaling hub in Arabidopsis. Mol Plant 7: 1598-1618

Pham VN, Kathare PK, Huq E (2018) Phytochromes and Phytochrome Interacting Factors. Plant Physiol 176: $1025-1038$

Piskacek S, Gregor M, Nemethova M, Grabner M, Kovarik P, Piskacek M (2007) Nineamino-acid transactivation domain: establishment and prediction utilities. Genomics 89: 756-768

Qiu Y (2020) Regulation of PIF4-mediated thermosensory growth. Plant Sci 297: 110541

Qiu Y, Li M, Kim RJ-A, Moore CM, Chen M (2019) Daytime temperature is sensed by phytochrome B in Arabidopsis through a transcriptional activator HEMERA. Nat Commun 10: 140 
Qiu Y, Li M, Pasoreck EK, Long L, Shi Y, Galvão RM, Chou CL, Wang H, Sun AY, Zhang YC, et al (2015) HEMERA Couples the Proteolysis and Transcriptional Activity of PHYTOCHROME INTERACTING FACTORs in Arabidopsis Photomorphogenesis. Plant Cell 27: 1409-1427

Qiu Y, Pasoreck EK, Yoo CY, He J, Wang H, Bajracharya A, Li M, Larsen HD, Cheung S, Chen M (2021) RCB initiates Arabidopsis thermomorphogenesis by stabilizing the thermoregulator PIF4 in the daytime. Nat Commun 12: 2042

Rengachari S, Schilbach S, Aibara S, Dienemann C (2021) Structure of the human MediatorRNA polymerase II pre-initiation complex. Nature

Robinson PJ, Trnka MJ, Bushnell DA, Davis RE, Mattei P-J, Burlingame AL, Kornberg RD (2016) Structure of a Complete Mediator-RNA Polymerase II Pre-Initiation Complex. Cell 166: 1411-1422.e16

Robinson PJ, Trnka MJ, Pellarin R, Greenberg CH, Bushnell DA, Davis R, Burlingame AL, Sali A, Kornberg RD (2015) Molecular architecture of the yeast Mediator complex. Elife. doi: 10.7554/eLife.08719

Sabari BR, Dall'Agnese A, Boija A, Klein IA, Coffey EL, Shrinivas K, Abraham BJ, Hannett NM, Zamudio AV, Manteiga JC, et al (2018) Coactivator condensation at superenhancers links phase separation and gene control. Science. doi: 10.1126/science.aar3958

Salladini E, Jørgensen MLM, Theisen FF, Skriver K (2020) Intrinsic Disorder in Plant Transcription Factor Systems: Functional Implications. Int J Mol Sci. doi: $10.3390 /$ ijms 21249755

Schilbach S, Hantsche M, Tegunov D, Dienemann C, Wigge C, Urlaub H, Cramer P (2017) Structures of transcription pre-initiation complex with TFIIH and Mediator. Nature 551: 204-209

Sidaway-Lee K, Costa MJ, Rand DA, Finkenstadt B, Penfield S (2014) Direct measurement of transcription rates reveals multiple mechanisms for configuration of the Arabidopsisambient temperature response. Genome Biol 15: R45

Soutourina J (2018) Transcription regulation by the Mediator complex. Nat Rev Mol Cell Biol 19: $262-274$

Stavang JA, Gallego-Bartolomé J, Gómez MD, Yoshida S, Asami T, Olsen JE, GarcíaMartínez JL, Alabadí D, Blázquez MA (2009) Hormonal regulation of temperatureinduced growth in Arabidopsis. Plant J 60: 589-601

Sun J, Qi L, Li Y, Chu J, Li C (2012) PIF4-mediated activation of YUCCA8 expression integrates temperature into the auxin pathway in regulating Arabidopsis hypocotyl growth. PLoS Genet 8: e1002594

Sun W, Han H, Deng L, Sun C, Xu Y, Lin L, Ren P, Zhao J, Zhai Q, Li C (2020) Mediator 
Subunit MED25 Physically Interacts with PHYTOCHROME INTERACTING FACTOR4 to Regulate Shade-Induced Hypocotyl Elongation in Tomato. Plant Physiol 184: 1549-1562

Tarczewska A, Greb-Markiewicz B (2019) The Significance of the Intrinsically Disordered Regions for the Functions of the bHLH Transcription Factors. Int J Mol Sci. doi: 10.3390/ijms20215306

Tóth-Petróczy A, Oldfield CJ, Simon I, Takagi Y, Dunker AK, Uversky VN, Fuxreiter M (2008) Malleable machines in transcription regulation: the mediator complex. PLoS Comput Biol 4: e1000243

Tsai K-L, Tomomori-Sato C, Sato S, Conaway RC, Conaway JW, Asturias FJ (2014) Subunit Architecture and Functional Modular Rearrangements of the Transcriptional Mediator Complex. Cell 158: 463

Tsai K-L, Yu X, Gopalan S, Chao T-C, Zhang Y, Florens L, Washburn MP, Murakami K, Conaway RC, Conaway JW, et al (2017) Mediator structure and rearrangements required for holoenzyme formation. Nature 544: 196-201

Vojnic E, Mourão A, Seizl M, Simon B, Wenzeck L, Larivière L, Baumli S, Baumgart K, Meisterernst M, Sattler M, et al (2011) Structure and VP16 binding of the Mediator Med25 activator interaction domain. Nat Struct Mol Biol 18: 404-409

Wang C, Du X, Mou Z (2016) The Mediator Complex Subunits MED14, MED15, and MED16 Are Involved in Defense Signaling Crosstalk in Arabidopsis. Front Plant Sci 7: 1947

Wu Z, Ietswaart R, Liu F, Yang H, Howard M, Dean C (2016) Quantitative regulation of FLC via coordinated transcriptional initiation and elongation. Proc Natl Acad Sci U S A 113: $218-223$

Yang Y, Li L, Qu L-J (2016) Plant Mediator complex and its critical functions in transcription regulation. J Integr Plant Biol 58: 106-118

Yoo CY, He J, Sang Q, Qiu Y, Long L, Kim RJ-A, Chong EG, Hahm J, Morffy N, Zhou P, et al (2021) Direct photoresponsive inhibition of a p53-like transcription activation domain in PIF3 by Arabidopsis phytochrome B. Nat Commun 12: 1-16

Zhang X, Yao J, Zhang Y, Sun Y, Mou Z (2013) The Arabidopsis Mediator complex subunits MED14/SWP and MED16/SFR6/IEN1 differentially regulate defense gene expression in plant immune responses. Plant J 75: 484-497

Zhao H, Young N, Kalchschmidt J, Lieberman J, El Khattabi L, Casellas R, Asturias FJ (2021) Structure of mammalian Mediator complex reveals Tail module architecture and interaction with a conserved core. Nat Commun 12: 1355

Zhu J-Y, Oh E, Wang T, Wang Z-Y (2016) TOC1-PIF4 interaction mediates the circadian gating of thermoresponsive growth in Arabidopsis. Nat Commun 7: 13692 
bioRxiv preprint doi: https://doi.org/10.1101/2022.03.02.482654; this version posted March 4, 2022. The copyright holder for this preprint

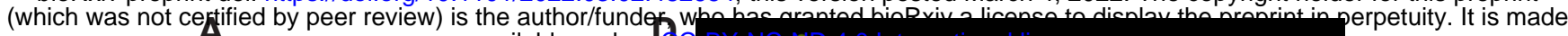
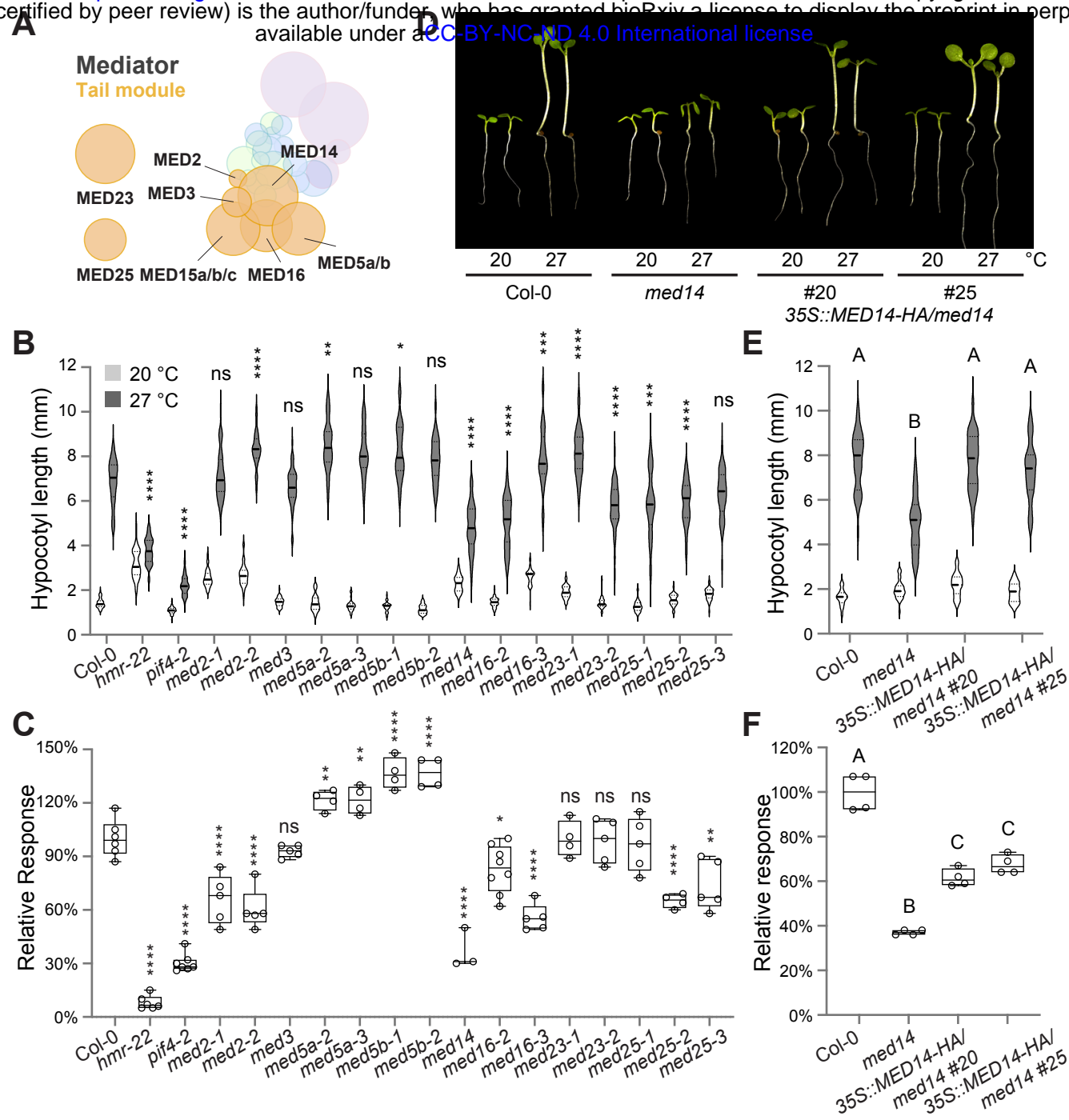

E

35S::MED14-HA/med14

Figure 1. MED14 is a crucial regulator of thermomorphogenesis.

(A) Schematic illustration of the Arabidopsis Mediator complex, with an emphasis on components in the tail module. The size of each circle reflects the relative protein size (predicted molecular weight) of each mediator subunit. The relative position of each mediator component is based on the cryo-EM and crystal structures of yeast and human Mediator (Tsai et al., 2014; Robinson et al., 2015) and interaction data of Arabidopsis mediator subunits (Maji et al., 2019). Note that the positions of MED23 and MED25 in the tail module are undetermined. Protein subunits in each module are colored in different colors: head module, green; middle module, blue; tail module, orange; cyclin kinase module, purple. See Supplemental Figure S1 for clear compositions of each module.

(B) Hypocotyl length measurements of mutant seedlings of mediator tail subunits. The white and grey bars represent hypocotyl length measurements at $20^{\circ} \mathrm{C}$ and $27^{\circ} \mathrm{C}$, respectively. The results of the one-way ANOVA analysis comparing the absolute hypocotyl length between Col- 0 and each mutant grown at $27^{\circ} \mathrm{C}$ are shown (n $>30) .{ }^{* * *}, p<0.0001 ;{ }^{* * *}, p<0.001 ;{ }^{* *}, p<0.01 ;{ }^{*}, p<0.05$; ns, not significant $(p \geq 0.05)$.

(C) Comparison of the relative thermal response among the seedlings in (B). The relative response is defined as the relative hypocotyl response to $27^{\circ} \mathrm{C}$ of a mutant compared with that of $\mathrm{Col}-0$ (which is set at $100 \%$ ). The results of the one-way ANOVA analysis comparing the relative response between Col- 0 and each mutant are shown $(\mathrm{n} \geq 3) .{ }^{* * *}, p<0.0001 ;{ }^{* * *}, p<0.001 ;{ }^{* *}, p<0.01 ;{ }^{*}, p<0.05$; ns, not significant $(p \geq 0.05)$.

(D) Representative images of 4-d-old Col-0, med14, and 35S::MED14-HA/med14 (\#20 and \#25) seedlings at either $20^{\circ} \mathrm{C}$ or $27^{\circ} \mathrm{C}$.

(E) Hypocotyl length measurements of seedlings in (D). Different letters denote significant statistical differences between the absolute hypocotyl length of each line grown at $27^{\circ} \mathrm{C}$ (one-way ANOVA, $\mathrm{n}>30, p<0.0001$ ).

$(F)$ Comparison of the relative thermal response among the seedlings in (D). Different letters denote significant statistical differences between the relative response of each line (one-way ANOVA, $\mathrm{n} \geq 4, p<0.0001$ ). 


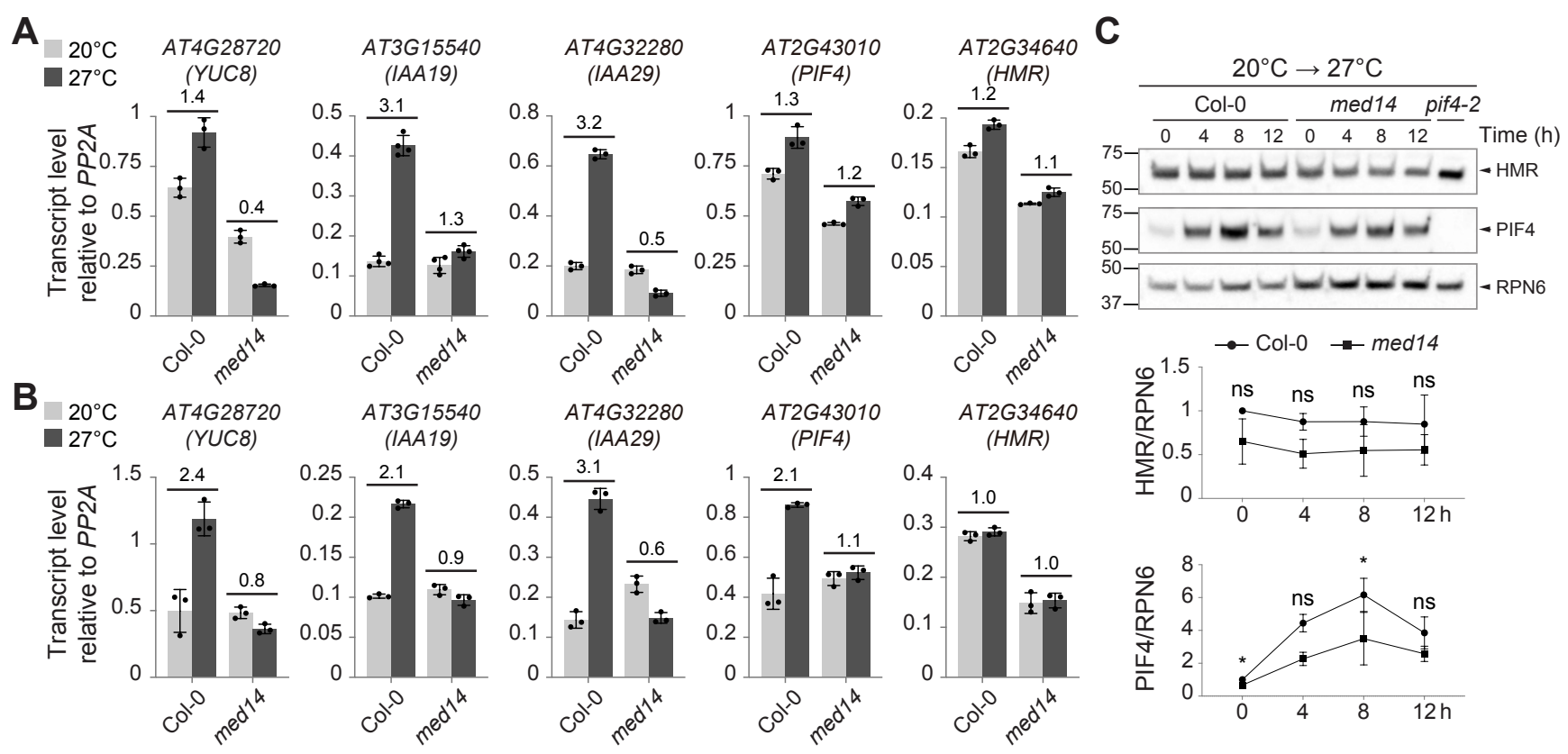

Figure 2. MED14 is required for the thermo-induced expression of PIF4 target genes.

(A) RT-qPCR analysis of the steady-state transcript levels of YUC8, IAA19, IAA29, PIF4, and HMR in Col-0 and med14 seedlings grown in $\mathrm{R}$ light for $96 \mathrm{~h}$ at $20^{\circ} \mathrm{C}$ and $27^{\circ} \mathrm{C}$. Numbers indicate the fold changes between transcript levels at these two temperatures.

(B) RT-qPCR analysis of the steady-state transcript levels of YUC8, IAA19, IAA29, PIF4, and HMR in Col-0 and med 14 during the $21^{\circ} \mathrm{C}$-to- $27^{\circ} \mathrm{C}$ transitions. Seedlings were grown in $\mathrm{R}$ light for $96 \mathrm{~h}$ and then transferred to $27^{\circ} \mathrm{C}$ in the same light condition. Samples were taken before (light grey) and $6 \mathrm{~h}$ after (dark grey) the $27^{\circ} \mathrm{C}$ treatment. Fold changes in the transcript levels by the $27^{\circ} \mathrm{C}$ treatment are shown above the columns. For $(A)$ and $(B)$, transcript levels were calculated relative to those of $P P 2 A$. Error bars represent the SD of three technical replicates.

(C) Immunoblot analysis of HMR and PIF4 levels in Col-0 and med 14 during the $21^{\circ} \mathrm{C}$-to- $27^{\circ} \mathrm{C}$ transitions. Seedlings were grown in R light for $96 \mathrm{~h}$ and then transferred to $27^{\circ} \mathrm{C}$ in the same light condition. Samples were collected and analyzed at the indicated time points. RPN6 was used as a loading control. The relative levels of HMR and PIF4, normalized to RPN6, are shown underneath the immunoblots. The results of the student t-test analysis are shown ( $\mathrm{n}=3$ or 4$)$. ${ }^{*}, p<0.05$; ns, not significant $(p \geq 0.05)$. 
bioRxiv preprint doi: https://doi.org/10.1101/2022.03.02.482654; this version posted March 4, 2022. The copyright holder for this preprint (which was not certified by peer review) is the author/funder, who has granted bioRxiv a license to display the preprint in perpetuity. It is made available under aCC-BY-NC-ND 4.0 International license.
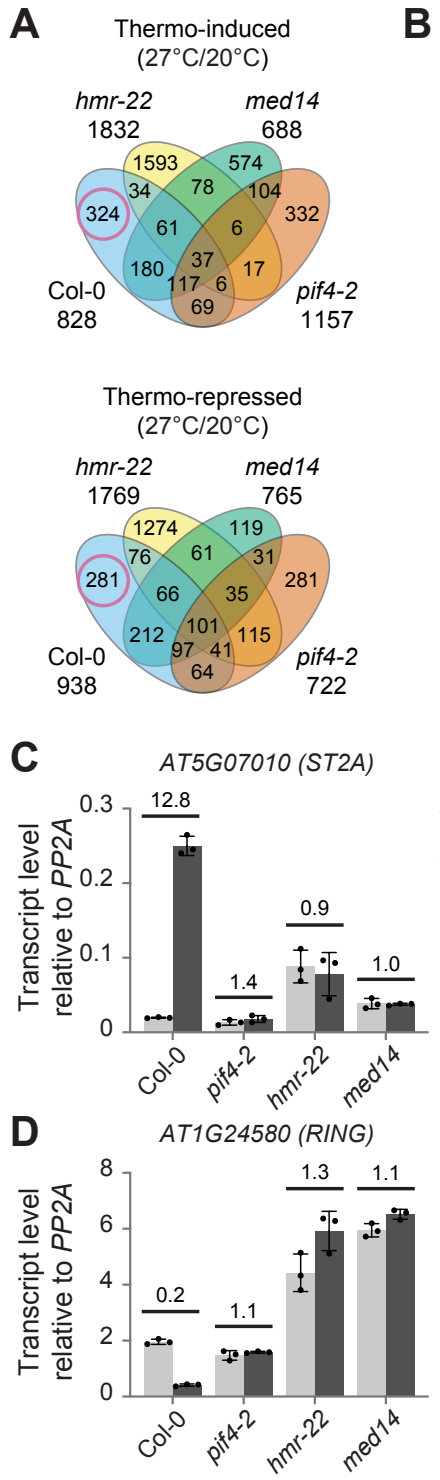
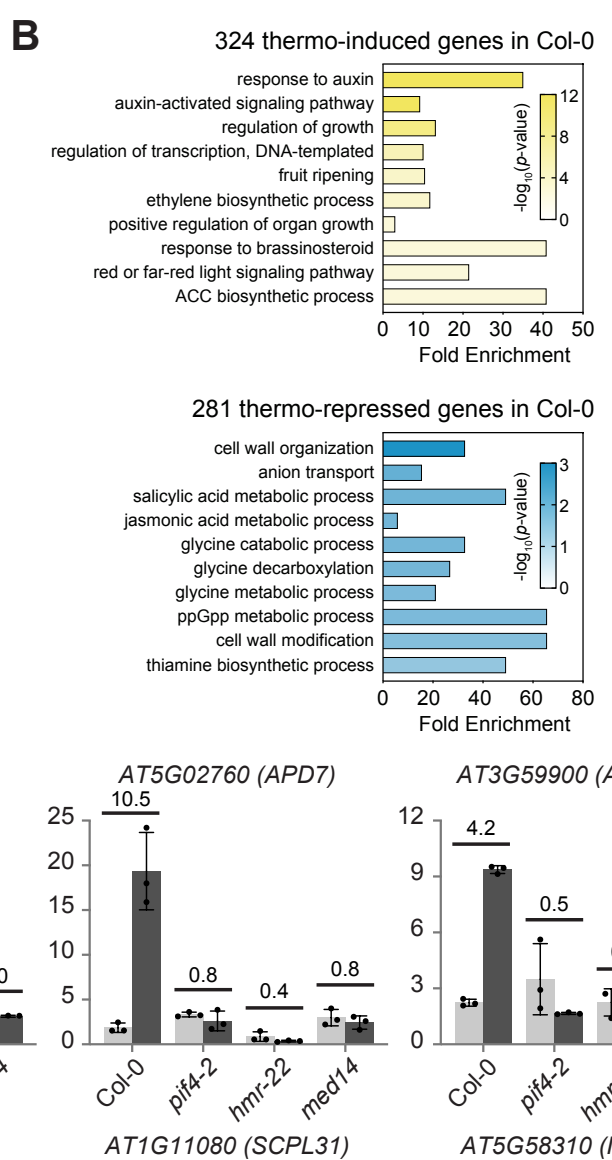

AT3G59900 (ARGOS)
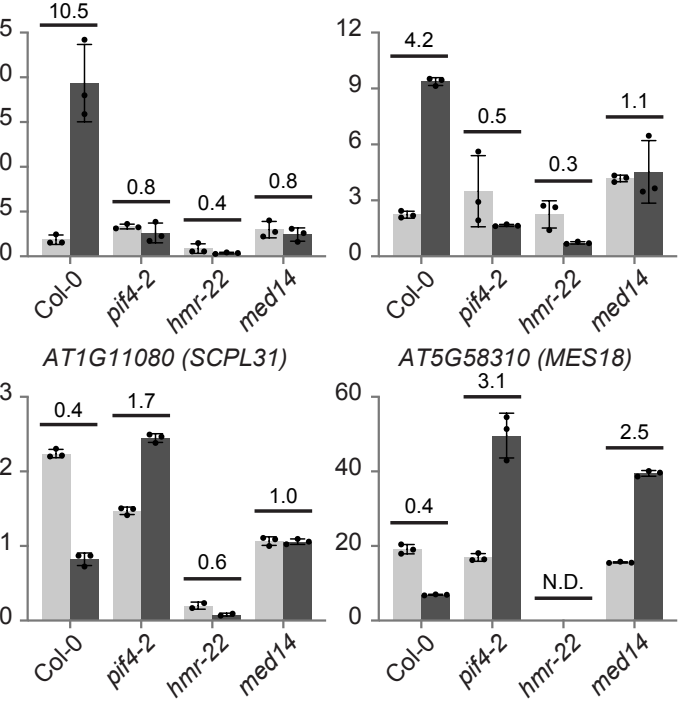

Figure 3. Thermo-induced expression of a group of auxin-related, growth-promoting genes requires PIF4, HMR, and MED14.

(A) A Venn diagram shows unique and co-regulated thermo-induced and thermo-repressed genes in wild type (Col-0), pif4-2, hmr-22, and med14 mutants. The red circles indicate PIF4/HMR/MED14-dependent genes that were uniquely induced and repressed in Col-0 but not in the mutants at $27^{\circ} \mathrm{C}$. Seedlings were grown in continuous red light for $96 \mathrm{~h}$ at either $20^{\circ} \mathrm{C}$ or $27^{\circ} \mathrm{C}$, and total RNA was extracted from four biological replicates for RNA-seq analyses.

(B) Gene ontology analysis of the 324 PIF4/HMR/MED14-dependent thermo-induced genes and 281 PIF4/HMR/MED14-dependent thermo-repressed genes. The bar represents the fold enrichment and the color indicates the $-\log _{10}$ (p-value). ACC, 1-aminocyclopropane-1-carboxylate (an ethylene precursor). ppGpp, guanosine tetraphosphate.

(C,D) RT-qPCR analysis of representative PIF4/HMR/MED14-dependent genes in Col-0, pif4-2, hmr-22, and med14. Total RNA was extracted from seedlings grown in continuous red light for $96 \mathrm{~h}$ at either $20^{\circ} \mathrm{C}$ or $27^{\circ} \mathrm{C}$. The relative expression of three thermo-induced (C) and three thermo-repressed genes (D) were normalized to the expression level of PP2A after RT-qPCR. Numbers indicate the fold changes between transcript levels at these two temperatures. N.D., not detected. 

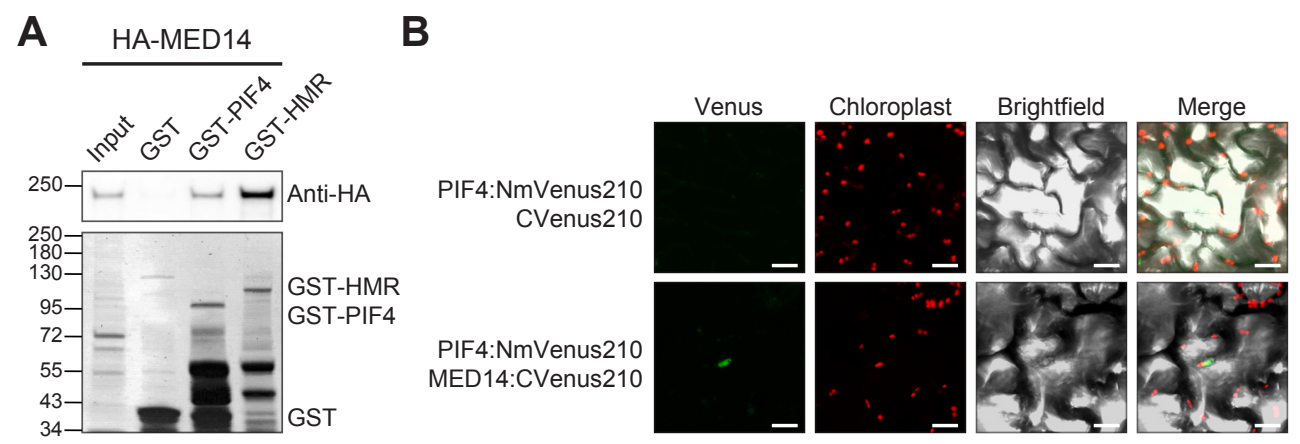

Figure 4. MED14 physically interacts with PIF4 and HMR.

(A) GST pull-down assays. GST-tagged full-length PIF4 and HMR were used as baits to pull down in vitro translated HA-tagged MED14. The upper panel is an immunoblot using anti-HA antibodies showing the bound and input fractions of HA-MED14; the lower panel is a Coomassie Blue-stained SDS-PAGE gel showing immobilized GST and GST-tagged PIF4 and HMR.

(B) Bimolecular fluorescence complementation assays. PIF4 fused with NmVenus210 (PIF4:NmVenus210) and MED14 fused with cVenus210 (MED14:CVenus210) were co-expressed in Nicotiana benthamiana through agroinfiltration. PIF4:NmVenus210 and CVenus210 were co-expressed as a control. The optical density of each Agrobacterium strain was 0.03 and images were captured $48 \mathrm{~h}$ after infiltration. The fluorescence signal (Venus) in the nucleus indicates the interactions between the two proteins tested in each agroinfiltration. The Chloroplast channel is to show that the Venus signal was not caused by the chlorophyll autofluorescence. Scale bars, $20 \mu \mathrm{m}$. 
bioRxiv preprint doi: https://doi.org/10.1101/2022.03.02.482654; this version posted March 4, 2022. The copyright holder for this preprint (which was not certified by peer review) is the author/funder, who has granted bioRxiv a license to display the preprint in perpetuity. It is made available under aCC-BY-NC-ND 4.0 International license.
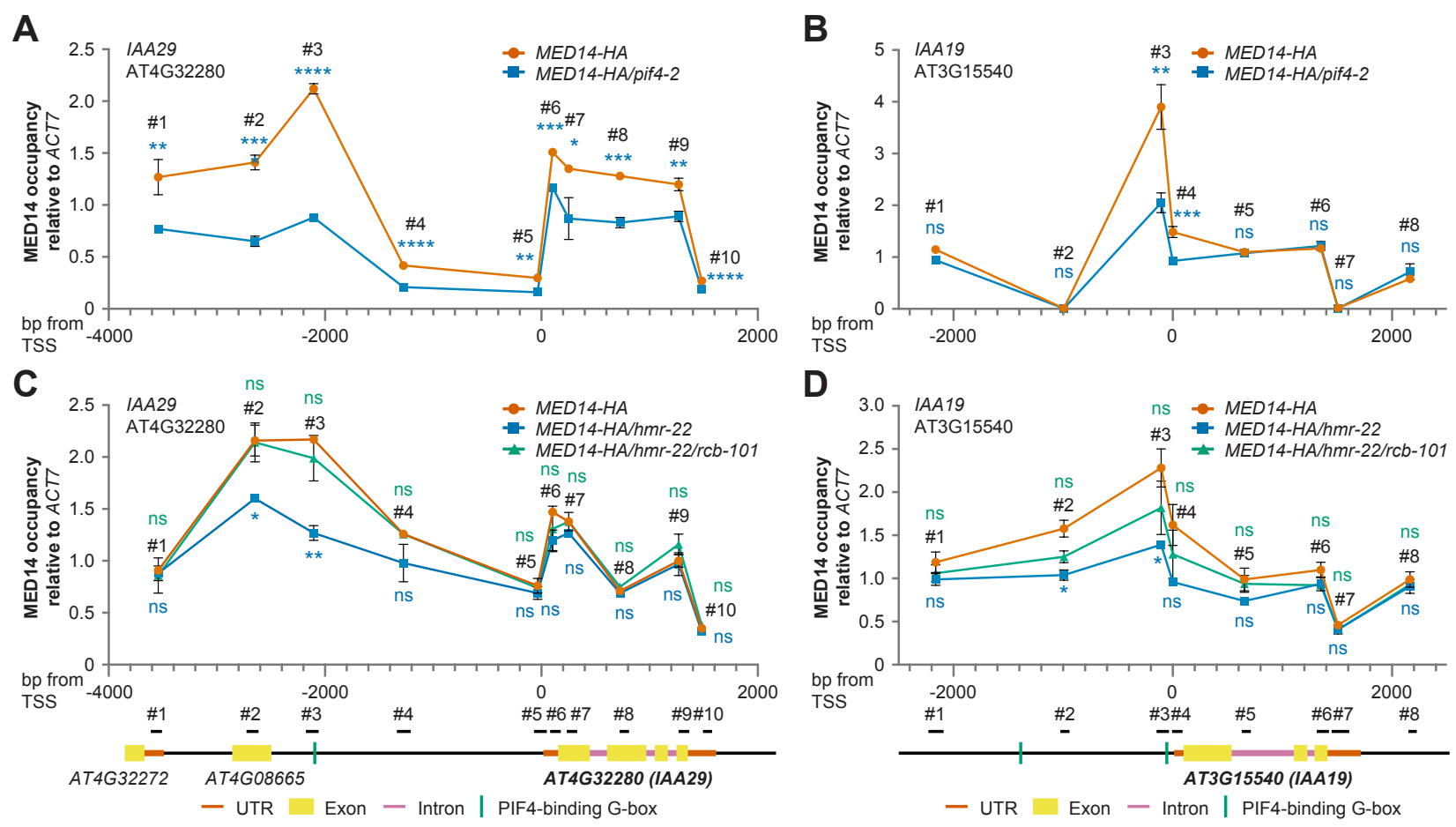

E

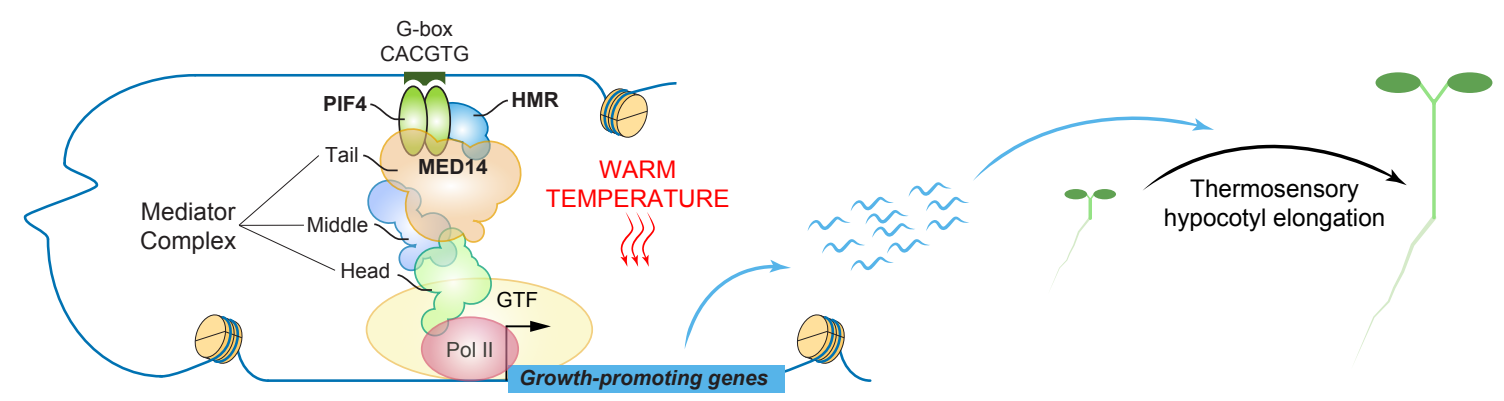

Figure 5. The association of MED14 with thermo-induced PIF4 direct targets is dependent on PIF4 and HMR.

ChIP-qPCR experiments compare MED14 occupancy across IAA29 (A and C) or IAA19 (B and D) in the presence and absence of functional PIF4 (A and B) or HMR ( $\mathrm{C}$ and D). Four-day-old $20^{\circ} \mathrm{C}$-grown MED14-HA, MED14-HA/pif4-2, MED14-HA/hmr-22, and MED14-HA/hmr-22/rcb-101 were treated at $27^{\circ} \mathrm{C}$ for 6 hours. HA antibody was used to assay MED14-HA association with each gene. Values are mean \pm SD from two independent samples, with data presented as the ratio of MED14-HA at IAA/input to MED14-HA at ACT7 $(+1912) /$ input. Student t-tests were used to compare the values between MED14-HA and other lines. ${ }^{* * * *}, p<$ $0.0001 ;{ }^{* *}, p<0.001 ;{ }^{* *}, p<0.01 ;{ }^{*}, p<0.05$; ns, not significant $(p \geq 0.05)$. The exact position of each PCR fragment is shown in the illustrations at the bottom and the primers are listed in Supplemental Table S4. The transcription start site (TSS) is the first nucleotide of the 5'UTR, as defined by the Araport11 genome annotation, released June 2016. (E) Schematic model for MED14 recruitment by PIF4 and HMR during the thermo-induced transcription of growth-promoting PIF4 target genes, the products of which subsequently promote thermosensory hypocotyl elongation. Pol II, RNA polymerase II; GTF, general transcription factors. The black arrow indicates the TSS. The size and proportions of the depicted components do not reflect their actual dimensions. 


\section{Parsed Citations} available under aCC-BY-NC-ND 4.0 International license.

Autran D, Jonak C, Belcram K, Beemster GTS, Kronenberger J, Grandjean O, Inzé D, Traas J (2002) Cell numbers and leaf development in Arabidopsis: a functional analysis of the STRUWWELPETER gene. EMBO J 21: 6036-6049

Google Scholar: Author Only Title Only Author and Title

Boija A, Klein IA, Sabari BR, Dall'Agnese A, Coffey EL, Zamudio AV, Li CH, Shrinivas K, Manteiga JC, Hannett NM, et al (2018) Transcription Factors Activate Genes through the Phase-Separation Capacity of Their Activation Domains. Cell 175: 18421855.e16

Google Scholar: Author Only Title Only Author and Title

Bordiya Y, Kim J, Xi Y, Kim D-H, Pyo Y, Zhao B, Zong W, Ricci WA, Zhang X, Sung S (2020) VL1, a Polycomb-associated protein, modulates high ambient temperature response via H3K27me3 and H2AZ in Arabidopsis thaliana. bioRxiv 2020.04.29.069484

Google Scholar: Author Only Title Only Author and Title

Borggrefe T, Yue X (2011) Interactions between subunits of the Mediator complex with gene-specific transcription factors. Semin Cell Dev Biol 22: 759-768

Google Scholar: Author Only Title Only Author and Title

Bourbon H-M (2008) Comparative genomics supports a deep evolutionary origin for the large, four-module transcriptional mediator complex. Nucleic Acids Res 36: 3993-4008

Google Scholar: Author Only Title Only Author and Title

Box MS, Huang BE, Domijan M, Jaeger KE, Khattak AK, Yoo SJ, Sedivy EL, Jones DM, Hearn TJ, Webb AAR, et al (2015) ELF3 controls thermoresponsive growth in Arabidopsis. Curr Biol 25: 194-199

Google Scholar: Author Only Title Only Author and Title

Buendía-Monreal M, Gillmor CS (2016) Mediator: A key regulator of plant development. Dev Biol 419: 7-18

Google Scholar: Author Only Title Only Author and Title

Casal JJ, Balasubramanian S (2019) Thermomorphogenesis. Annu Rev Plant Biol 70: 321-346

Google Scholar: Author Only Title Only Author and Title

Cevher MA, Shi Y, Li D, Chait BT, Malik S, Roeder RG (2014) Reconstitution of active human core Mediator complex reveals a critical role of the MED14 subunit. Nat Struct Mol Biol 21: 1028-1034

Google Scholar: Author Only Title Only Author and Title

Chen M, Galvão RM, Li M, Burger B, Bugea J, Bolado J, Chory J (2010) Arabidopsis HEMERApTAC12 initiates

photomorphogenesis by phytochromes. Cell 141: 1230-1240

Google Scholar: Author Only Title Only Author and Title

Chen X, Yin X, Li J, Wu Z, Qi Y, Wang X, Liu W, Xu Y (2021) Structures of the human Mediator and Mediator-bound preinitiation complex. Science. doi: 10.1126/science.abg0635

Google Scholar: Author Only Title Only Author and Title

Cortijo S, Charoensawan V, Brestovitsky A, Buning R, Ravarani C, Rhodes D, van Noort J, Jaeger KE, Wigge PA(2017)

Transcriptional Regulation of the Ambient Temperature Response by H2AZ Nucleosomes and HSF1 Transcription Factors in

Arabidopsis. Mol Plant 10: 1258-1273

Google Scholar: Author Only Title Only Author and Title

Dalton JC, Bätz U, Liu J, Curie GL, Quail PH (2016) AModified Reverse One-Hybrid Screen Identifies Transcriptional Activation Domains in PHYTOCHROME-INTERACTING FACTOR 3. Front Plant Sci 7: 881

Google Scholar: Author Only Title Only Author and Title

Ding L, Wang S, Song Z-T, Jiang Y, Han J-J, Lu S-J, Li L, Liu J-X (2018) Two B-Box Domain Proteins, BBX18 and BBX23, Interact with ELF3 and Regulate Thermomorphogenesis in Arabidopsis. Cell Rep 25: 1718-1728.e4

Google Scholar: Author Only Title Only Author and Title

Dolan WL, Chapple C (2017) Conservation and Divergence of Mediator Structure and Function: Insights from Plants. Plant Cell Physiol 58: 4-21

Google Scholar: Author Only Title Only Author and Title

Dolan WL, Dilkes BP, Stout JM, Bonawitz ND, Chapple C (2017) Mediator complex subunits MED2, MED5, MED16, and MED23 genetically interact in the regulation of phenylpropanoid biosynthesis. Plant Cell 29: 3269-3285

Google Scholar: Author Only Title Only Author and Title

Dotson MR, Yuan CX, Roeder RG, Myers LC, Gustafsson CM, Jiang YW, Li Y, Kornberg RD, Asturias FJ (2000) Structural organization of yeast and mammalian mediator complexes. Proc Natl Acad Sci U S A97: 14307-14310

Google Scholar: Author Only Title Only Author and Title 
Fornero C, Rickerd T, Kirik V (2019) Papillae formation on Arabidopsis leaf trichomes requires the function of Mediator tail subunits 2, 14, 15a, 16, and 25. Planta 249: 1063-1071

Google Scholar: Author Only Title Only Author and Title

Franklin KA, Lee SH, Patel D, Kumar SV, Spartz AK, Gu C, Ye S, Yu P, Breen G, Cohen JD, et al (2011) Phytochrome-interacting factor 4 (PIF4) regulates auxin biosynthesis at high temperature. Proc Natl Acad Sci U S A108: 20231-20235

Google Scholar: Author Only Title Only Author and Title

García-Moreno A, López-Domínguez R, Ramirez-Mena A, Pascual-Montano A, Aparicio-Puerta E, Hackenberg M, Carmona-Saez P (2021) GeneCodis 4: Expanding the modular enrichment analysis to regulatory elements. bioRxiv 2021.04.15.439962

Google Scholar: Author Only Title Only Author and Title

Gookin TE, Assmann SM (2014) Significant reduction of BiFC non-specific assembly facilitates in planta assessment of heterotrimeric G-protein interactors. Plant J 80: 553-567

Google Scholar: Author Only Title Only Author and Title

Han X, Yu H, Yuan R, Yang Y, An F, Qin G (2019) Arabidopsis Transcription Factor TCP5 Controls Plant Thermomorphogenesis by Positively Regulating PIF4 Activity. iScience 15: 611-622

Google Scholar: Author Only Title Only Author and Title

Hemsley PA, Hurst CH, Kaliyadasa E, Lamb R, Knight MR, De Cothi EA, Steele JF, Knight H (2014) The Arabidopsis mediator complex subunits MED16, MED14, and MED2 regulate mediator and RNA polymerase II recruitment to CBF-responsive coldregulated genes. Plant Cell 26: 465-484

Google Scholar: Author Only Title Only Author and Title

Jeronimo C, Robert F (2017) The Mediator Complex: At the Nexus of RNAPolymerase II Transcription. Trends Cell Biol 27: 765783

Google Scholar: Author Only Title Only Author and Title

Jin H, Lin J, Zhu Z(2020) PIF4 and HOOKLESS1 Impinge on Common Transcriptome and Isoform Regulation in Thermomorphogenesis. Plant Commun 1: 100034

Google Scholar: Author Only Title Only Author and Title

Kim S, Hwang G, Kim S, Thi TN, Kim H, Jeong J, Kim J, Kim J, Choi G, Oh E (2020) The epidermis coordinates thermoresponsive growth through the phyB-PIF4-auxin pathway. Nat Commun 11: 1053

Google Scholar: Author Only Title Only Author and Title

Koini MA, Avey L, Alen T, Tilley CA, Harberd NP, Whitelam GC, Franklin KA(2009) High temperature-mediated adaptations in plant architecture require the bHLH transcription factor PIF4. Curr Biol 19: 408-413

Google Scholar: Author Only Title Only Author and Title

Kumar SV, Lucyshyn D, Jaeger KE, Alós E, Alvey E, Harberd NP, Wigge PA(2012) Transcription factor PIF4 controls the thermosensory activation of flowering. Nature 484: 242-245

Google Scholar: Author Only Title Only Author and Title

Lee M, Dominguez-Ferreras A, Kaliyadasa E, Huang W-J, Antony E, Stevenson T, Lehmann S, Schäfer P, Knight MR, Ntoukakis V, et al (2021a) Mediator Subunits MED16, MED14, and MED2 Are Required for Activation of ABRE-Dependent Transcription in Arabidopsis. Front Plant Sci 12: 649720

Google Scholar: Author Only Title Only Author and Title

Lee S, Paik I, Huq E (2020) SPAs promote thermomorphogenesis by regulating the phyB-PIF4 module in Arabidopsis.

Development. doi: 10.1242/dev.189233

Google Scholar: Author Only Title Only Author and Title

Lee S, Wang W, Huq E (2021b) Spatial regulation of thermomorphogenesis by HY5 and PIF4 in Arabidopsis. Nat Commun 12 : 3656 Google Scholar: Author Only Title Only Author and Title

Lee S, Zhu L, Huq E (2021c) An autoregulatory negative feedback loop controls thermomorphogenesis in Arabidopsis. PLoS Genet 17: e1009595

Google Scholar: Author Only Title Only Author and Title

Leivar P, Monte E (2014) PIFs: systems integrators in plant development. Plant Cell 26: 56-78

Google Scholar: Author Only Title Only Author and Title

Leivar P, Monte E, Oka Y, Liu T, Carle C, Castillon A, Huq E, Quail PH (2008) Multiple phytochrome-interacting bHLH transcription factors repress premature seedling photomorphogenesis in darkness. Curr Biol 18: 1815-1823

Google Scholar: Author Only Title Only Author and Title

Leivar P, Quail PH (2011) PIFs: pivotal components in a cellular signaling hub. Trends Plant Sci 16: 19-28

Google Scholar: Author Only Title Only Author and Title 
bioRxiv preprint doi: https://doi.org/10.1101/2022.03.02.482654; this version posted March 4, 2022. The copyright holder for this preprint

(which was not certified by peer review) is the author/funder, who has granted bioRxiv a license to display the preprint in perpetuity. It is made available under aCC-BY-NC-ND 4.0 International license.

Liu H-C, Charng Y-Y (2013) Common and distinct functions of Arabidopsis class A1 and A2 heat shock factors in diverse abiotic stress responses and development. Plant Physiol 163: 276-290

Google Scholar: Author Only Title Only Author and Title

Liu J, Perumal NB, Oldfield CJ, Su EW, Uversky VN, Dunker AK (2006) Intrinsic disorder in transcription factors. Biochemistry 45: 6873-6888

Google Scholar: Author Only Title Only Author and Title

Ludwig W, Hayes S, Trenner J, Delker C, Quint M (2021) On the evolution of plant thermomorphogenesis. J Exp Bot. doi:

10.1093/jxb/erab310

Google Scholar: Author Only Title Only Author and Title

Ma D, Li X, Guo Y, Chu J, Fang S, Yan C, Noel JP, Liu H (2016) Cryptochrome 1 interacts with PIF4 to regulate high temperaturemediated hypocotyl elongation in response to blue light. Proc Natl Acad Sci U S A113: 224-229

Google Scholar: Author Only Title Only Author and Title

Maji S, Dahiya P, Waseem M, Dwivedi N, Bhat DS, Dar TH, Thakur JK (2019) Interaction map of Arabidopsis Mediator complex expounding its topology. Nucleic Acids Res 47: 3904-3920

Google Scholar: Author Only Title Only Author and Title

Malik S, Roeder RG (2010) The metazoan Mediator co-activator complex as an integrative hub for transcriptional regulation. Nat Rev Genet 11: 761-772

Google Scholar: Author Only Title Only Author and Title

Nagulapalli M, Maji S, Dwivedi N, Dahiya P, Thakur JK (2016) Evolution of disorder in Mediator complex and its functional relevance. Nucleic Acids Res 44: 1591-1612

Google Scholar: Author Only Title Only Author and Title

Nevarez PA, Qiu Y, Inoue H, Yoo CY, Benfey PN, Schnell DJ, Chen M (2017) Mechanism of Dual Targeting of the Phytochrome Signaling Component HEMERAPTAC12 to Plastids and the Nucleus. Plant Physiol 173: 1953-1966

Google Scholar: Author Only Title Only Author and Title

Nozawa K, Schneider TR, Cramer P (2017) Core Mediator structure at 3.4 Âextends model of transcription initiation complex. Nature 545: 248-251

Google Scholar: Author Only Title Only Author and Title

Ohama N, Moo TL, Chua N-H (2020) Differential requirement of MED14/17 recruitment for activation of heat inducible genes. New Phytol. doi: 10.1111/nph.17119

Google Scholar: Author Only Title Only Author and Title

Oh E, Zhu JY, Wang ZY (2012) Interaction between BZR1 and PIF4 integrates brassinosteroid and environmental responses. Nat. Cell Biol.

Google Scholar: Author Only Title Only Author and Title

Park Y-J, Kim JY, Lee J-H, Han S-H, Park C-M (2021) External and Internal Reshaping of Plant Thermomorphogenesis. Trends Plant Sci 26: 810-821

Google Scholar: Author Only Title Only Author and Title

Park Y-J, Lee H-J, Ha J-H, Kim JY, Park C-M (2017) COP1 conveys warm temperature information to hypocotyl

thermomorphogenesis. New Phytol 215: 269-280

Google Scholar: Author Only Title Only Author and Title

Pedmale UV, Huang S-SC, Zander M, Cole BJ, Hetzel J, Ljung K, Reis PAB, Sridevi P, Nito K, Nery JR, et al (2016) Cryptochromes Interact Directly with PIFs to Control Plant Growth in Limiting Blue Light. Cell 164: 233-245

Google Scholar: Author Only Title Only Author and Title

Pfeiffer A, Shi H, Tepperman JM, Zhang Y, Quail PH (2014) Combinatorial complexity in a transcriptionally centered signaling hub in Arabidopsis. Mol Plant 7: 1598-1618

Google Scholar: Author Only Title Only Author and Title

Pham VN, Kathare PK, Huq E (2018) Phytochromes and Phytochrome Interacting Factors. Plant Physiol 176: 1025-1038

Google Scholar: Author Only Title Only Author and Title

Piskacek S, Gregor M, Nemethova M, Grabner M, Kovarik P, Piskacek M (2007) Nine-amino-acid transactivation domain: establishment and prediction utilities. Genomics 89: 756-768

Google Scholar: Author Only Title Only Author and Title

Qiu Y (2020) Regulation of PIF4-mediated thermosensory growth. Plant Sci 297: 110541

Google Scholar: Author Only Title Only Author and Title

Qiu Y, Li M, Kim RJ-A, Moore CM, Chen M (2019) Daytime temperature is sensed by phytochrome B in Arabidopsis through a 

available under aCC-BY-NC-ND 4.0 International license.

transcriptional activator HEMERA Nat Commun 10: 140

Google Scholar: Author Only Title Only $\underline{\text { Author and Title }}$

Qiu Y, Li M, Pasoreck EK, Long L, Shi Y, Galvão RM, Chou CL, Wang H, Sun AY, Zhang YC, et al (2015) HEMERACouples the Proteolysis and Transcriptional Activity of PHYTOCHROME INTERACTING FACTORs in Arabidopsis Photomorphogenesis. Plant Cell 27: 1409-1427

Google Scholar: Author Only Title Only Author and Title

Qiu Y, Pasoreck EK, Yoo CY, He J, Wang H, Bajracharya A, Li M, Larsen HD, Cheung S, Chen M (2021) RCB initiates Arabidopsis thermomorphogenesis by stabilizing the thermoregulator PIF4 in the daytime. Nat Commun 12: 2042

Google Scholar: Author Only Title Only Author and Title

Rengachari S, Schilbach S, Aibara S, Dienemann C (2021) Structure of the human Mediator-RNA polymerase II pre-initiation complex. Nature

Google Scholar: Author Only Title Only Author and Title

Robinson PJ, Trnka MJ, Bushnell DA, Davis RE, Mattei P-J, Burlingame AL, Kornberg RD (2016) Structure of a Complete Mediator-RNAPolymerase II Pre-Initiation Complex. Cell 166: 1411-1422.e16

Google Scholar: Author Only Title Only Author and Title

Robinson PJ, Trnka MJ, Pellarin R, Greenberg CH, Bushnell DA, Davis R, Burlingame AL, Sali A, Kornberg RD (2015) Molecular architecture of the yeast Mediator complex. Elife. doi: 10.7554/eLife.08719

Google Scholar: Author Only Title Only Author and Title

Sabari BR, Dall'Agnese A, Boija A, Klein IA, Coffey EL, Shrinivas K, Abraham BJ, Hannett NM, Zamudio AV, Manteiga JC, et al (2018) Coactivator condensation at super-enhancers links phase separation and gene control. Science. doi:

10.1126/science.aar3958

Google Scholar: Author Only Title Only Author and Title

Salladini E, Jørgensen MLM, Theisen FF, Skriver K (2020) Intrinsic Disorder in Plant Transcription Factor Systems: Functional Implications. Int J Mol Sci. doi: 10.3390/ijms21249755

Google Scholar: Author Only Title Only Author and Title

Schilbach S, Hantsche M, Tegunov D, Dienemann C, Wigge C, Urlaub H, Cramer P (2017) Structures of transcription pre-initiation complex with TFIIH and Mediator. Nature 551: 204-209

Google Scholar: Author Only Title Only Author and Title

Sidaway-Lee K, Costa MJ, Rand DA, Finkenstadt B, Penfield S (2014) Direct measurement of transcription rates reveals multiple mechanisms for configuration of the Arabidopsisambient temperature response. Genome Biol 15: R45

Google Scholar: Author Only Title Only Author and Title

Soutourina J (2018) Transcription regulation by the Mediator complex. Nat Rev Mol Cell Biol 19: 262-274

Google Scholar: Author Only Title Only Author and Title

Stavang JA, Gallego-Bartolomé J, Gómez MD, Yoshida S, Asami T, Olsen JE, García-Martínez JL, Alabadí D, Blázquez MA(2009) Hormonal regulation of temperature-induced growth in Arabidopsis. Plant J 60: 589-601

Google Scholar: Author Only Title Only Author and Title

Sun J, Qi L, Li Y, Chu J, Li C (2012) PIF4-mediated activation of YUCCA8 expression integrates temperature into the auxin pathway in regulating Arabidopsis hypocotyl growth. PLoS Genet 8: e1002594

Google Scholar: Author Only Title Only Author and Title

Sun W, Han H, Deng L, Sun C, Xu Y, Lin L, Ren P, Zhao J, Zhai Q, Li C (2020) Mediator Subunit MED25 Physically Interacts with PHYTOCHROME INTERACTING FACTOR4 to Regulate Shade-Induced Hypocotyl Elongation in Tomato. Plant Physiol 184: 15491562

Google Scholar: Author Only Title Only Author and Title

Tarczewska A, Greb-Markiewicz B (2019) The Significance of the Intrinsically Disordered Regions for the Functions of the bHLH Transcription Factors. Int J Mol Sci. doi: 10.3390/ijms20215306

Google Scholar: Author Only Title Only Author and Title

Tóth-Petróczy A, Oldfield CJ, Simon I, Takagi Y, Dunker AK, Uversky VN, Fuxreiter M (2008) Malleable machines in transcription regulation: the mediator complex. PLoS Comput Biol 4: e1000243

Google Scholar: Author Only Title Only Author and Title

Tsai K-L, Tomomori-Sato C, Sato S, Conaway RC, Conaway JW, Asturias FJ (2014) Subunit Architecture and Functional Modular Rearrangements of the Transcriptional Mediator Complex. Cell 158: 463

Google Scholar: Author Only Title Only Author and Title

Tsai K-L, Yu X, Gopalan S, Chao T-C, Zhang Y, Florens L, Washburn MP, Murakami K, Conaway RC, Conaway JW, et al (2017) 
bioRxiv preprint doi: https://doi.org/10.1101/2022.03.02.482654; this version posted March 4, 2022. The copyright holder for this preprint (which was not certified by peer review) is the author/funder, who has granted bioRxiv a license to display the preprint in perpetuity. It is made available under aCC-BY-NC-ND 4.0 International license.

Mediator structure and rearrangements required for holoenzyme formation. Nature 544: 196-201

Google Scholar: Author Only Title Only Author and Title

Vojnic E, Mourão A, Seizl M, Simon B, Wenzeck L, Larivière L, Baumli S, Baumgart K, Meisterernst M, Sattler M, et al (2011) Structure and VP16 binding of the Mediator Med25 activator interaction domain. Nat Struct Mol Biol 18: 404-409

Google Scholar: Author Only Title Only Author and Title

Wang C, Du X, Mou Z(2016) The Mediator Complex Subunits MED14, MED15, and MED16 Are Involved in Defense Signaling Crosstalk in Arabidopsis. Front Plant Sci 7: 1947

Google Scholar: Author Only Title Only Author and Title

Wu Z, letswaart R, Liu F, Yang H, Howard M, Dean C (2016) Quantitative regulation of FLC via coordinated transcriptional initiation and elongation. Proc Natl Acad Sci U S A113: 218-223

Google Scholar: Author Only Title Only Author and Title

Yang Y, Li L, Qu L-J (2016) Plant Mediator complex and its critical functions in transcription regulation. J Integr Plant Biol 58: 106118

Google Scholar: Author Only Title Only Author and Title

Yoo CY, He J, Sang Q, Qiu Y, Long L, Kim RJ-A, Chong EG, Hahm J, Morffy N, Zhou P, et al (2021) Direct photoresponsive inhibition of a p53-like transcription activation domain in PIF3 by Arabidopsis phytochrome B. Nat Commun 12: 1-16

Google Scholar: Author Only Title Only $\underline{\text { Author and Title }}$

Zhang X, Yao J, Zhang Y, Sun Y, Mou Z(2013) The Arabidopsis Mediator complex subunits MED14/SWP and MED16/SFR6/IEN1 differentially regulate defense gene expression in plant immune responses. Plant J 75: 484-497

Google Scholar: Author Only Title Only Author and Title

Zhao H, Young N, Kalchschmidt J, Lieberman J, El Khattabi L, Casellas R, Asturias FJ (2021) Structure of mammalian Mediator complex reveals Tail module architecture and interaction with a conserved core. Nat Commun 12: 1355

Google Scholar: Author Only Title Only Author and Title

Zhu J-Y, Oh E, Wang T, Wang Z-Y (2016) TOC1-PIF4 interaction mediates the circadian gating of thermoresponsive growth in Arabidopsis. Nat Commun 7: 13692

Google Scholar: Author Only Title Only Author and Title 